\title{
New to teaching geography
}

Royal Geographical Society

with IBG

Advancing geography

and geographical learning

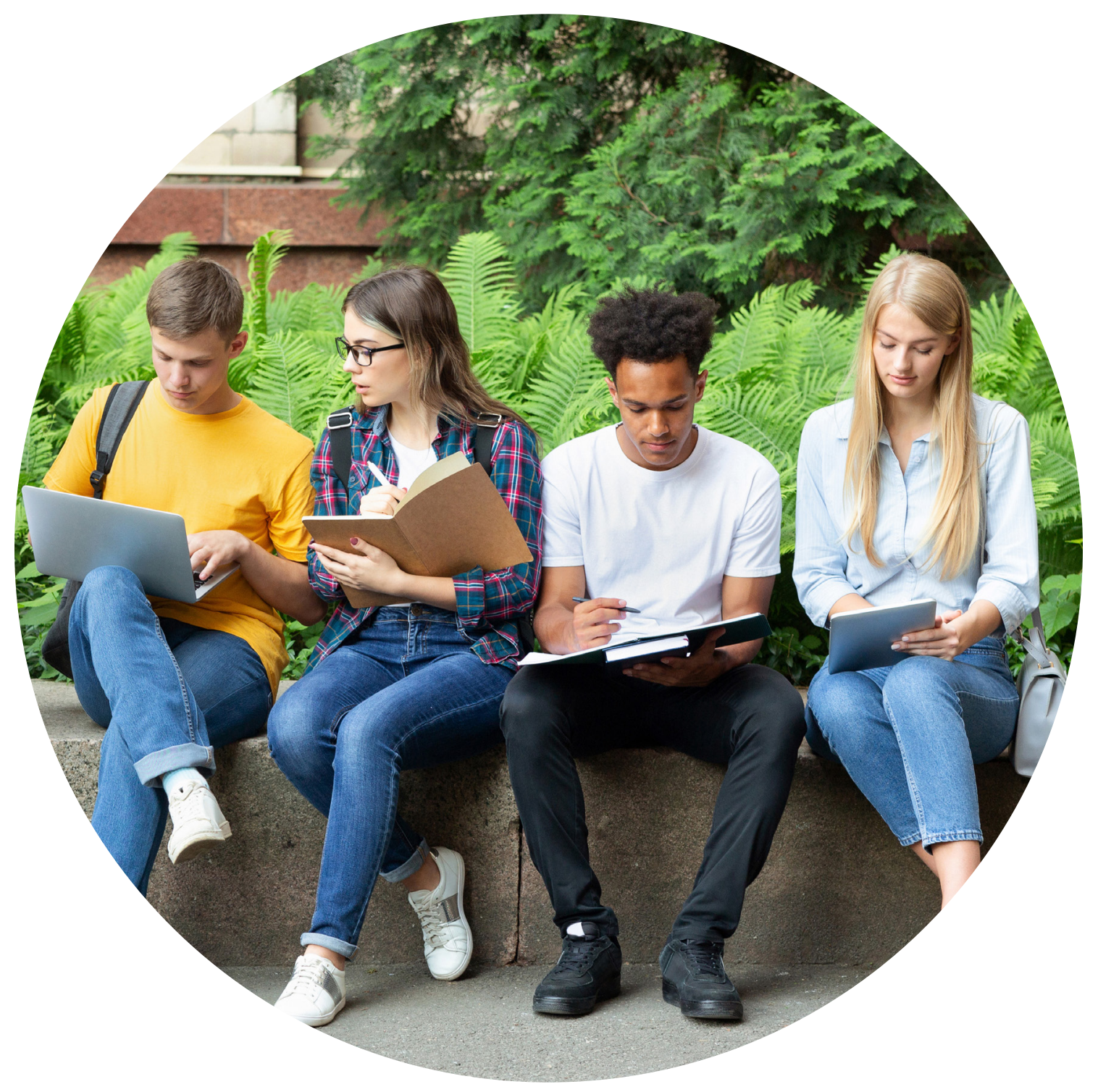

A practical guide for higher education teaching assistants, teaching fellows and demonstrators.

Lynda Yorke, Simon Tate and Martin Davis 


\section{Acknowledgements}

$\bullet \bullet \bullet \bullet \bullet \bullet \bullet \bullet \bullet \bullet \bullet \bullet \bullet \bullet \bullet \bullet \bullet \bullet$

This guide is better because of the many people who took time to read and comment upon our ideas at various stages. Firstly, many thanks must go to our colleagues at the Royal Geographical Society (with IBG) for taking the time to consider our original proposal for a teaching guide and to the anonymous reviewers for their constructive feedback on an earlier draft of the text. In particular, we are grateful to Catherine Souch for her unwavering support and perceptive comments throughout the writing process. An engaging conversation with Kim Peters at the RGSIBG Annual International Conference in 2019 helped to shape the text at a formative stage.

We are also heavily indebted to the colleagues, from several universities, who took the time to contribute text to many of the chapters: Carl Bonner-Thompson, James Esson, James Flanders, Des McDougall and Maddy Thompson. The guide is better for their expertise and their contributions help to ensure that this guide reflects better the breadth and diversity of teaching within our geographical community.

Thank you. 


\section{Introduction}

Geography plays a crucial role in understanding our world. It makes a vital contribution to our knowledge of the rapidly changing environmental and social challenges facing us and how we should tackle them. Engaging higher education students with these issues and supporting them effectively can present multiple opportunities and challenges for academic staff for academic staff. For those embarking on a career in geographical teaching and learning, recognising these issues, and developing a toolbox of strategies with which to address them, is key to developing good teaching practice. This guide offers a starting point for this process for graduate teaching assistants, teaching fellows and demonstrators.

Over the last two decades, former Higher Education Academy's GEES Subject Centre, and more recently the Royal Geographical Society (with IBG), have been offering workshops, events and resources for those new to teaching geography, earth and environmental science (GEES) in higher education. Those events continue, now mainly online, and address topics such as: geography's signature pedagogies, with a particular, with a particular focus on fieldwork; how we teach; creating effective learning environments, in person and online; student learning styles; and assessment and feedback. In so doing, they introduce educators to relevant networks and resources.

\section{Dr Lynda Yorke (Bangor University) and Prof. Simon} Tate (Newcastle University) have led several such events in recent years, supported by Dr Martin Davis (RGS-IBG). Enhanced by additional content by experts in the field, this introductory guide is intended to complement and support these events, signposting some of the key issues raised, new and emerging topics and approaches that warrant more attention. While this guide is by no means exhaustive in its treatment of any of these topics, it is our hope that the concepts, ideas and resources outlined will act as a springboard for further exploration of these issues, a process which will continue throughout your career. The approach taken and topics included have been shaped by conversations and critical discussions with graduate teaching assistants (GTAs) and demonstrators at recent events and, consequently, it is envisaged that these groups may find this guide most useful. While the guide's focus is on teaching geography in $\mathrm{HE}$, the ideas presented will resonate more widely with those teaching subjects such as earth science, environmental science and geology.

The teaching and learning community within our discipline is active and vibrant, and some of the great resources developed by members of the the geography teaching community teaching community are signposted in this guide. While it has not been possible to include every activity, resource and group in this guide, we encourage you to engage with the excellent range of high-quality work being undertaken by colleagues across the discipline. While the guide has been written in the context of higher education in the UK, we hope that many of the concepts and ideas presented will be helpful further afield too.

Learning through geography helps us all to be more socially and environmentally sensitive, better informed, and more responsible as citizens and employees. As you seek to teach and inspire others with this diverse and fascinating subject, we hope this guide will be a helpful resource.

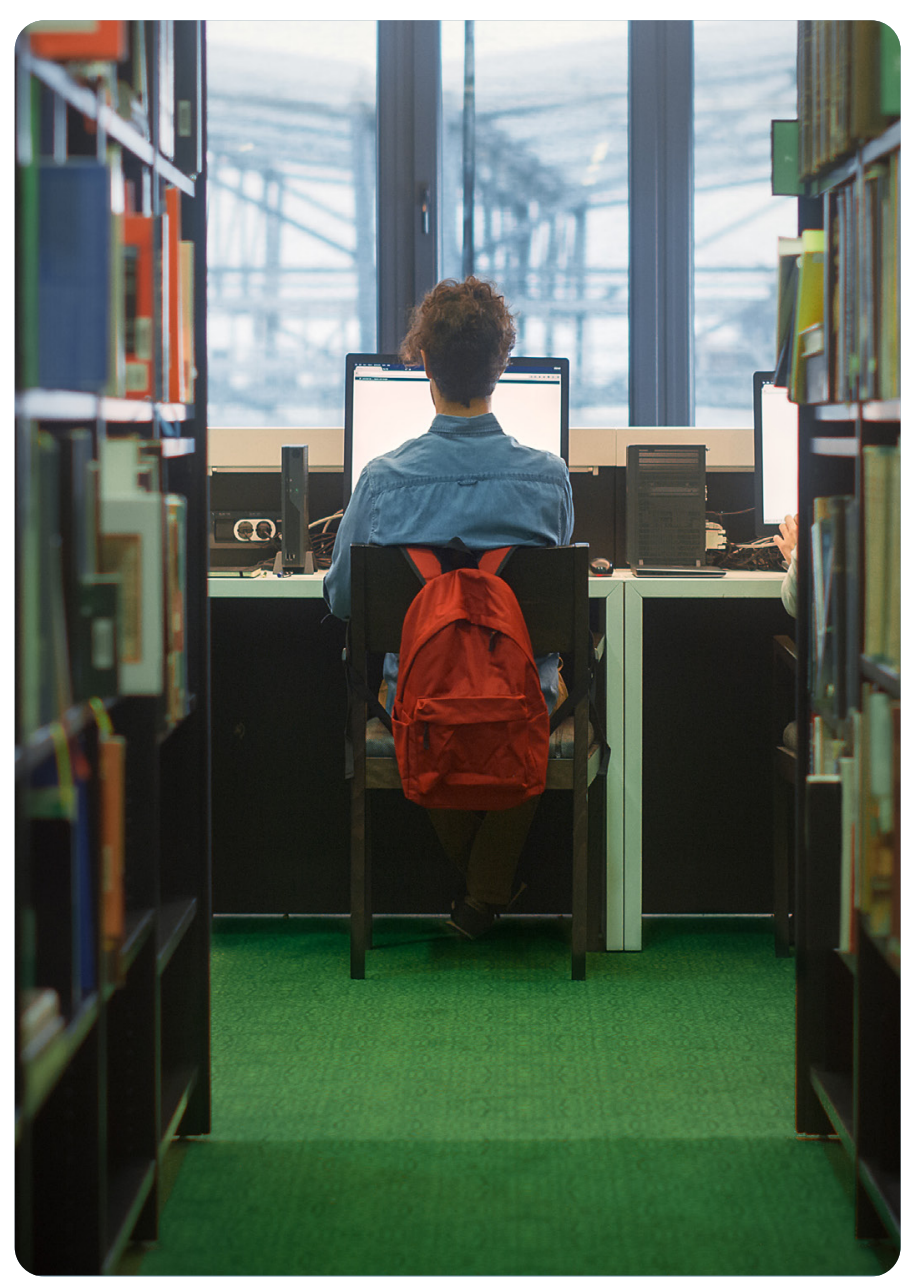




\section{Understanding your approach to teaching and learning}

\section{What is pedagogy?}

Pedagogy is a word you often hear in higher education. Educators often talk about their 'pedagogical approach' to teaching. But what does it mean? One way to think about pedagogy is as the method, and practice, of teaching as opposed to the content of what is taught. Pedagogy encompasses teaching styles, teaching theory and our approach to assessment and feedback. Another way to think about pedagogy is the way we (as a community of practitioners teaching geography) reflect on what we know about our students and their needs, and how we use this to shape the delivery of content in our classes. Consequently, when we plan any teaching - whether it's a lecture, seminar, lab class or fieldwork; whether it's in person or online - we need to consider different ways to deliver the content. These decisions become our pedagogical principles or pedagogic approach. Our decisions will be guided by our own teaching preferences, our experience, the context in which we are teaching, and by our knowledge of teaching theory and what that tells us about how best to deliver content to achieve our aims for the students.

The literature on pedagogy is rich and diverse. Some is generic in focus (e.g. Bates, 2019), while some is geographically focussed (e.g. Walkington, Hill and Dyer, 2019). If you are undertaking a Postgraduate Certificate in Higher Education (such as a PGCertHE or PGCAP) or considering applying for Fellowship of AdvanceHE, you will need to engage with this literature as it provides a strong foundation on which you can build effective teaching practices. In the rest of this chapter, we introduce some of the key pedagogical questions it is helpful to address when planning any teaching.

\section{Which generic pedagogies will I use?}

Generic pedagogies are those which can be used in (m)any subjects. Here we will briefly consider some of the more commonly discussed approaches.

Behaviourism is a teacher-centred pedagogy, which has its origins in the research conducted by Thorndike (1905), Pavlov (1955) and Skinner (1938; 1948; 1971). Its basic premise is that students want to learn but need strong direction to do so effectively. Consequently, for behaviourists, the teacher should be the sole authority figure - in control of what needs to be achieved by the class and the means to achieve it. To help with this, behaviourists favour the use of direct instruction and transmissive learning - knowledge is transmitted from the teacher to their class. In a lesson using a behaviourist pedagogical approach, you can expect to see lecturing and demonstrating. Behaviourism can be a means to deliver fact-based knowledge, usually to large groups of students, in an efficient way.

Behaviourism has critics who argue that it is prone to ignoring individual differences, and doesn't explicitly encourage students to think deeply, critically or evaluatively about what they are learning. Many of the critics of behaviourists are constructivists.

Constructivism is based on the research of Piaget (1936), who believed that students come ready to learn, and that the role of the teacher is to create an environment and activities to facilitate their learning by encouraging self-discovery and reflection. In other words, constructivists believe that students learn best when they construct knowledge, rather than just receiving it. Consequently, constructivisits put students at the centre of the learning process and incorporate project work, enquiry-based learning and problembased learning as a means to encourage "deep learning" (Everaert et al., 2017) and to encourage students to think critically and evaluatively about what they are learning, by making arguments and forming judgements. Constructivists believe that they encourage students to develop high-order thinking skills (Bloom et al., 1956).

\begin{tabular}{|c|c|l|}
\hline Evaluation & \multirow{4}{*}{ High } & $\begin{array}{l}\text { Judge, evaluate, support, } \\
\text { criticise, select, recognise }\end{array}$ \\
Synthesis & & $\begin{array}{l}\text { Summarise, argue, relate, } \\
\text { organise, generalise, conclude }\end{array}$ \\
Analysis & $\begin{array}{l}\text { Select, compare, separate, } \\
\text { differentiate, contrast }\end{array}$ \\
\cline { 1 - 1 } Application & $\begin{array}{l}\text { Predict, select, assess, show, } \\
\text { use construct, compute }\end{array}$ \\
Comprehension & $\begin{array}{l}\text { Identify, illustrate, represent, } \\
\text { explain, contrast }\end{array}$ \\
Knowledge & Low & $\begin{array}{l}\text { Write, state, recall, reproduce, } \\
\text { describe }\end{array}$ \\
\hline
\end{tabular}


Of course, we shouldn't just accept Bloom's ideas. Common critiques of Bloom's Taxonomy revolve around the way it is perceived to prescribe a necessary pathway for learning that requires moving up the hierarchy. It is said to place knowledge/remembering at the bottom where it is perceived as least important. However, often we don't start by remembering things, then understanding them, then applying them. Instead, we can build understanding by applying knowledge and by creating things (see Anderson and Krathwohl, 2001). Likewise, sometimes it is more helpful to think about knowledge/remembering more positively, as a foundation learners need and upon which we can build.

Related to Constructivism, is Social Constructivism, which was developed by Len Vygotsky (1978). The key difference between Piaget's Constructivism and Vygotsky's Social Constructivism is that Piaget believed that self-discovery is crucial to learning, whereas Vygotsky stated that learning is best achieved by working with more knowledgeable others - whether that is interacting with family, friends, teachers or peers. Consequently, in addition to using project work, enquiry-based learning and problem-based learning as a means to encourage "deep learning" (Biggs, 2001), social constructivists also favour group-work, class discussions, debates and role-plays (Bates, 2019).

Other important, and often used, pedagogic ideas associated with Vygotsky are "the zone of proximal development" and "scaffolding" (although it is worth noting that Vygotsky never actually used the word "scaffolding"). The zone of proximal development is the range of tasks a student can perform with help and guidance but cannot yet perform independently. It is the zone we want our students to be working in as, according to Vygotsky, it is here that the greatest learning takes place.

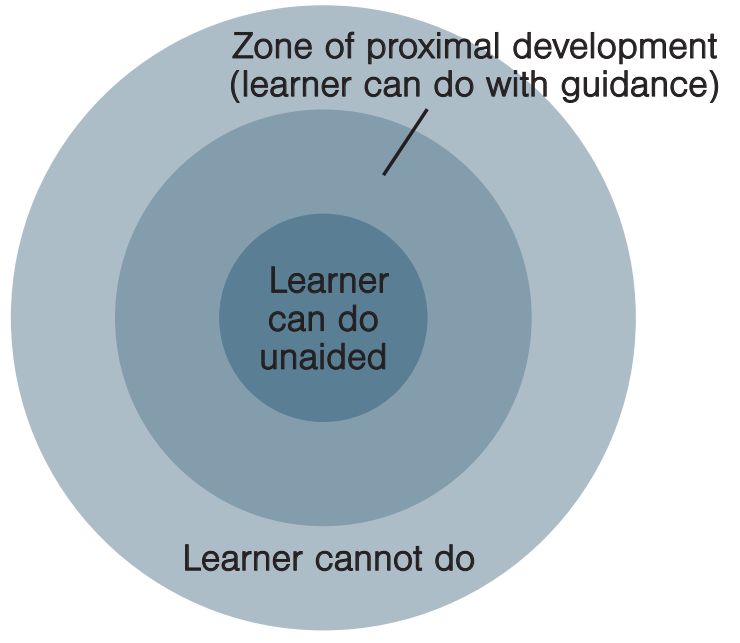

Figure 2: Vygotsky's Zone of Proximal Development (adapted from Vygotsky, 1978)
Scaffolding is the support mechanism that helps a learner successfully perform a task within his or her zone of proximal development. Scaffolding can take many forms: for example, it could be a well-directed question in a seminar; an introductory lecture at the start of a project; assistance with using some equipment in the field; or a handout explaining how to do a task. The skill of a social constructivist is to design tasks in a way that allows them to adjust how much help or scaffolding to give each student as the class takes place: too little and the student won't be able to do the task and won't learn effectively; too much and the task may become too easy for the student, or we may end up moving too far towards transmissive, passive learning, where the student stops constructing knowledge and instead just receives it.

Many contemporary ideas in teaching - students as partners in curriculum planning (Bovill, 2020), students as researchers (Bovill, 2020), learning for work (Yorke and Knight, 2006), technology-enhanced learning (Kirkwood and Price, 2014) - are to an extent underpinned by Constructivism or Social Constructivism. Yet, both Constructivism or Social Constructivism have critics who dislike their focus on individual processing and interpretation as the best way to produce understanding. This, it has been claimed, is too subjective, too unscientific and an inefficient way to help students to understand commonly accepted knowledge (e.g. Liu and Matthews, 2005).

While Behaviourism, Constructivism and Social Constructivism are helpful theoretical starting points to begin to scope out the range of possible approaches we can adopt in our teaching (there are also others), in practice it can be unhelpful to adopt an approach to our teaching that is too singular and inflexible. For example, a lecture that includes a breakout discussion might incorporate both behaviourist and social constructivist approaches. Important questions to ask ahead of each class are: what am I trying to achieve in terms of student learning outcomes? What is the best way to do this? 


\section{Which signature pedagogical approaches will I use?}

Shulman (2005: 52) defines signature pedagogies as "the types of teaching that organise the fundamental ways in which future practitioners are educated for their new professions". According to Shulman, a signature pedagogy has three dimensions: surface structure, deep structure, and an implicit structure. The surface structure consists of concrete, operational acts of teaching and learning, while deep structures reflect a set of assumptions about how best to impart knowledge. The implicit structure comprises a set of beliefs about professional attitudes, values and dispositions.

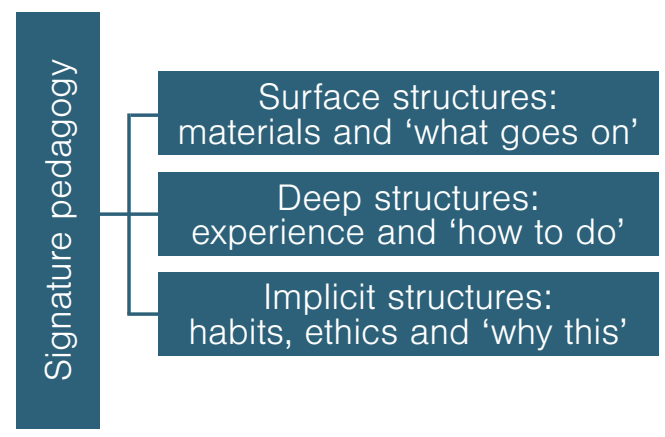

Figure 3: Signature pedagogies (adapted from Schulman, 2005)

So, what are geography's signature pedagogies and how can we find out more about them? Firstly, there is fieldwork. As the Fieldwork Principles of Geography (RGS-IBG, 2020) and the Subject Benchmark Statement for Geography (QAA, 2022) make clear, fieldwork is central to the geographical tradition and to the teaching of geography. It provides geographers with a unique opportunity for experiential active learning (learning by doing) that inspires students' engagement with the subject. It reflects that realworld learning and context-based applied learning are fundamental to understanding, and changing, our world. Virtual reality fieldwork and online fieldwork are increasingly important within geography. However, many types of fieldwork are immersive and/or cannot be replicated virtually or online.

A second signature pedagogy in geography is mapping or cartography, which has evolved with technological change to include spatial analysis and geospatial data visualisation. While this can take many forms, as a signature pedagogy of geography it helps students to see the connections between places and scales that other subjects overlook. For example, we might ask students to think in a spatial way about an issue or the effect of space and place on an issue. It is this kind of spatial thinking that separates political geography from politics, economic geography from economics or biogeography from biology. At the other end of the spectrum, it could also mean asking students to work quantitively with big data to produce GIS maps or visualisations.

A third signature pedagogy of geography requires thinking in a holistic or integrated way about the relationships between natural science, social sciences and humanities; between human and physical geography; and the inter-relations between natural, human and non-human environments. In other words, geographers are particularly interested in how people impact the environment and environmental processes and how these processes, in turn, impact people.

You will need to use both generic and signature pedagogies in your teaching - one isn't better than the other and it would be difficult to deliver a geography class without using generic pedagogies. However, your students would struggle to develop their 'geographical lens', their 'geography value-added', if you didn't employ some signature pedagogies as well. The key is to find the right blend of generic and signature pedagogies to deliver geographical learning to your class in the most effective way.

In addition to developing a broad range of generic and transferable skills as part of their degree, the use of signature pedagogies ensures that students also develop geographical skills, which together mark geographers out as distinct, and which provide the basis for employability and lifelong learning (for a list of these geographical skills, see QAA, 2022).

Implicit in geography's signature pedagogies are the compassionate and considerate values and beliefs that we want to nurture in our geography students. These are outlined in the Subject Benchmark Statement (QAA, 2022) as being ethical and sustainable awareness and reflection, and geography's role in transformative justice and practices of solidarity. Geographers' values and beliefs are also summed up effectively by the former president of the RGS-IBG, Nick Crane:

"Studying geography also helps us to understand many of the issues we face in Britain and globally, such as how we might respond to the impact of climate change or be better prepared for natural hazards... 
helping us to navigate through the world's geographically complex people, places and environments" (Crane, quoted by the RGSIBG, 2017).

Another way to ensure that our pedagogical approach is geographical is to think about how we engage with 'threshold concepts'. Meyer and Land (2003:

1) define a threshold concept "as akin to a portal, opening up a new and previously inaccessible way of thinking about something. It represents a transformed way of understanding, or interpreting, or viewing something without which the learner cannot progress". Consequently, focussing on these threshold concepts or 'big ideas' in our teaching is another way of encouraging our students to think geographically. Place, space and scale, time, connections, processes and systems are all threshold concepts in geography.

We are fortunate in geography to have a strong tradition of scholarship which draws on these signature pedagogies and threshold concepts. Pedagogic journals include the Journal of Geography in Higher Education, the Journal of Environmental Education, Environmental Education Research and the Journal of Geoscience Education. In addition, the teaching blog 'What works for learning and teaching in HE GEES?' provides a constantly updated bank of practical tips on effective teaching in GEES subjects, as does the teaching section of the RGS-IBG website and the GeolSoc website. There are also excellent pedagogic books to support your geography teaching, such as the Handbook for Teaching and Learning in Geography (Walkington, Hill and Dyer, 2019).

\section{Pedagogies for practical teaching}

One way to think about the importance of practical teaching in geography is to use David Kolb's Theory of Experiential Learning or The Experiential Learning Cycle $(1984 ; 2015)$, which is typically represented in four-stages. Despite some criticism of this model (e.g. Coffield et al., 2004; Meittinen 2000), it remains influential (Seaman et al., 2017) and it has recently been revised by Morris (2019). Effective learning happens when a person progresses from having a concrete experience (e.g. 'hands on' in the field); to a period of observation and critical reflection on that experience; which leads to the formation of abstract concepts (analysis) and generalisations (conclusions).

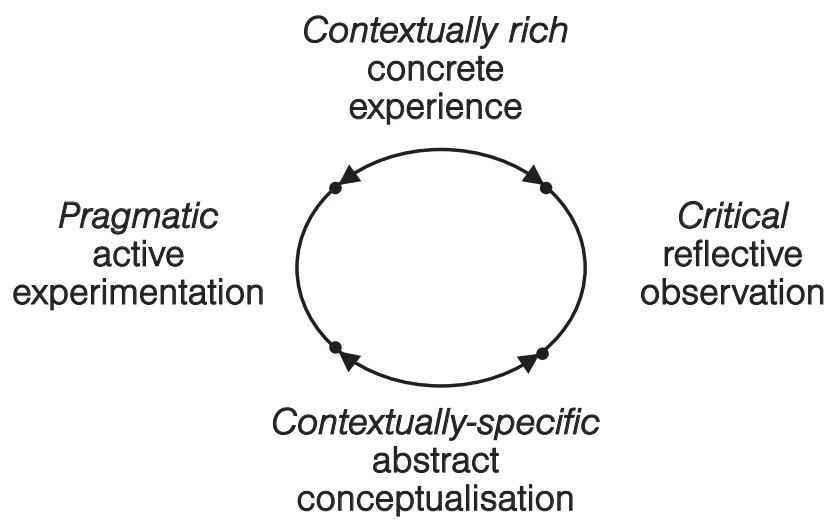

Figure 4: Kolb's Experiential Learning Cycle (adapted from Kolb, 1984; 2015)

From this model we can see that we need to incorporate any field or practical experience within a broader 'package' of teaching which allows space for reflection. Thinking back to the pedagogic ideas of Bloom, we can appreciate that an important part of practical teaching is the way it encourages learners to think deeply, critically or evaluatively about what they are learning. Students are moved from surface learning to deep learning because practical teaching involves problem-solving or working through a series of actions in order to generate data. It epitomises experiential learning by doing. 


\section{Developing your pedagogic approach}

This chapter presents ideas to think about and reflect upon for each teaching session that we plan to deliver. In reality, many of these are decisions that are taken early in our teaching career and we then embed them as part of our own pedagogical principles or pedagogic approach. In other words, they become part of our teaching style - our core approach to teaching, with which we are comfortable and which over time we know is effective.

That said, while we all develop our own pedagogical principles over time, it is really important to remain conscious of, and to keep reflecting on, these: questioning the choices we make about how best to deliver content; asking ourselves if there are better ways; experimenting with new ideas; improving our knowledge of pedagogic theory; and adapting our pedagogical principles accordingly. The best teachers are nearly always highly reflexive teachers - they know how they teach and why, but always wonder if there is a better way.

Schön (1994) distinguishes between reflectionin-action and reflection-on-action. Reflection-inaction is reflection during the 'doing' stage, such as making small changes to a lesson plan during a class to improve students' learning or being responsive in the moment to students' needs. Reflection-on-action, on the other hand, involves reflecting on how practice can be developed after the lesson has been taught. Reflection-on-action can be informed by self-questioning, discussions with other colleagues and/or students, observations and feedback, and pedagogic literature. 


\section{Creating effective learning environments in person and online}

\section{Teaching effectively in person and online}

While the Covid-19 pandemic brought online learning to the fore, many geography degrees already included an online component to their teaching. It is unlikely that we will revert to teaching geography without an online component and so, as geographical educators, we need to be confident that we can create effective learning environments in both physical and online spaces. As a starting point, there are some terms we need to be aware of: synchronous, asynchronous, blended, hybrid, HyFlex and flipped classroom are the most often used. As well as being aware of what mode of delivery the class(es) you are teaching will employ, it is important to understand how they fit into the broader module design and whether the module leader is employing blended learning or a flipped classroom approach or something different again.

Synchronous teaching: this takes place when the educator is present at the same time as their students. This is almost always the case in a physical environment such as a classroom, but synchronous teaching can also take place online, using webinars (live online lessons), group chats, drop-in sessions or instant messaging.

Asynchronous teaching: this takes place when teaching materials are posted online and students work through them in their own time, communicating with each other and the teacher via discussion boards, Virtual Learning Environments (VLE), email or other fora. In order to promote active learning and to appeal to a wide range of learning preferences, asynchronous teaching will include a variety of media, including audio and video clips, as well as tasks and activities.

Blended learning: this form of teaching combines online and in-person learning. Many students are doing some form of blended learning and have been for years. Blended learning may include both synchronous and asynchronous delivery.
HyFlex: is a course design model that gives students the option of attending sessions in the classroom or participating online. Educators deliver classes in person and synchronously to online students at the same time. Often there is also an asynchronous online option. Students can decide how they want to participate.

Flipped classroom: a particular type of blended learning where students are introduced to a topic asynchronously (e.g. through online content such as a pre-recorded lecture or via readings and activities) and then acquire a deeper understanding of the material in a synchronous learning environment (such as an in-person seminar, online webinar, a workshop or lab class). A flipped classroom reverses the traditional model of teaching geography, where students are introduced to ideas in class and subsequently develop their understanding through independent learning tasks. While the order changes, the same principles of active, deep learning, within a pedagogical framework of Constructivism or Social Constructivism (see Chapter 1), apply.

As a teaching assistant or teaching fellow, it is most likely that you will be engaged in some form of synchronous teaching, whether in person or online, whether as part of a blended or flipped classroom approach. This could mean delivering seminars, webinars, tutorials and workshops, or assisting with computer practicals, lab classes or fieldwork. Often, it is assumed that in-person and online teaching require very different pedagogical approaches. However, similar pedagogic principles can be applied to creating effective learning in both environments. Applying the pedagogical ideas of Constructivism and Social Constructivism to any of these types of classes, means developing environments that engage students in active learning - whether that's tasks to complete, quizzes to answer, or issues to think through and discuss with peers, with you as the teacher, or collectively as a class. It also means minimising the time that you spend delivering a 'mini-lecture' of information which students passively receive. These principles hold true whether the classes you are delivering are in person, blended or completely online. 
Often it is assumed that in-person and online learning require very different pedagogical approaches. However, similar pedagogic principles can be applied to creating effective learning in both environments.

\section{Facilitating dialogue in person and online}

Whether in person or online, it can be daunting for students to give their thoughts in a public environment, in front of a class and a teacher they might not know particularly well. One approach to understanding what we can do to help students to view these learning environments positively comes from the work of Maslow (1943; 1954). As a psychologist, Maslow suggested that all humans are motivated by certain needs and that these are hierarchical: it is not possible, Maslow suggested, to address higher order needs if the ones lower down the hierarchy have not been met.

Self

actualisation

Esteem

Belonging

Safety

Physiological

Figure 5: Maslow's Hierarchy of Needs (adapted for HE teaching from Maslow, 1943; 1954)

\section{Self-actualisation}

Students need to feel that in the classroom, they are using their talents and abilities to the fullest and leave the class knowing they have met the learning outcomes.

\section{Esteem}

Students need to feel valued and respected by other members of the group and by us as educators. Positive feedback and constructive criticism that feeds forward are good ways to build students' esteem (see Chapter 6).

\section{Belonging}

As educators we need to create an inclusive space, where all students feel engaged as part of a group that is learning together.

\section{Safety}

As educators we need to create psychologically safe spaces where students can ask questions and learn without too many inhibitions.

\section{Physiological}

As a pre-requisite to learning effectively, students need to be well-fed, well-hydrated, well-rested, working in a room with a comfortable temperature and good lighting.

Since learning geography in higher education requires students to self-actualise at the top of Maslow's hierarchy, it follows that we must do what we can as geographical educators to ensure that students' needs at the other levels of the hierarchy are met. While ensuring many of the physiological needs Maslow identified are beyond what can be reasonably expected, as geography educators we do have a pivotal role to play in making the spaces in which we teach psychologically safe and inclusive, in turn engendering a sense of belonging and esteem.

So, what practical things can make a difference? If you are teaching a group of students for the first time, or even if you've been together in the classroom previously, make sure you introduce yourself. Chatting with students before the class about non-academic things, with open body language (i.e. arms not crossed over your body, hands not on hips, etc.), can help to break down barriers and make you seem personable and friendly. If you are teaching online, try recording an introductory video or write some text about yourself. Perhaps show or describe your personal workspace 
and the view out your window, talk about your hobbies, passions, or pets - it shows you're human! Ask your students to do the same; it helps to understand their situation, to create a sense of collective endeavour and belonging and will give you ideas for learning activities that draw on their interests.

Use interpersonal communication effectively to create an environment in which everyone feels able to participate in their own way and to make mistakes without being judged.

Particularly, if you are teaching the same group of students several times, give the students plenty of opportunities to get to know each other - perhaps by playing 'name-chains' or 'two truths and a lie', which give everyone the chance to begin to interact and make mistakes in a low-stakes way. To get started with name chains, ask the students to sit in a circle which you join. Next, say your name and the place you are from. Then, prompt the student sitting next to you to say their name and where they're from, followed by your information. The second student in the circle must then say their information, the first student's information and then your information. Continue this until the last student attempts to remember the information of everyone in the room. Encourage your students that it's not as hard as it sounds - but also that making mistakes and helping each other out is part of the ice-breaking experience. This sort of activity can also be adapted to the aims of the class. For example, when playing name chains, you can ask students to replace where they are from with what they want to take from today's class. When teaching online, remembering students' names becomes easier as often these are displayed on screen. Consequently, as an online icebreaker, 'two truths and a lie' usually works well. Students take it in turn to give three facts about themselves and the rest of the group must guess which is the lie. While some see these sorts of activities as 'wasted time', from Maslow we can see that they are essential precursors to creating an effective learning environment in which students feel comfortable discussing and constructing knowledge. These low-stakes activities can also have an important EDI dimension, as they help students (such as those from under-represented backgrounds or those with specific learning difficulties) to become more comfortable in their new learning environments.
Finally, consider the configuration of the teaching space and its influence on student interaction. For example, setting classroom desks out in a circle of which you are part, may be more conducive to discussion than setting the desks out in rows, with you standing at the front of the class or behind a desk, which forms a physical and psychological barrier between you and the students. In an online space, it could be that breakout rooms which you dip in and out of to facilitate learning are more conducive to discussion than keeping the class together as a whole. It could also be the case that breakout rooms encourage students to switch on their webcams - body language is a major component of communication and, while there are compelling EDI and wellbeing reasons not to require all students to turn on their webcam (e.g. Palin, 2020; Moses, 2020), we shouldn't underestimate the importance of encouraging eye contact when conducting classes online.

If the technology you are using allows, set up online classes so that you control switching students' microphones on and off, but allow students control of their own webcams. This minimises background noise, while allowing students to control who can see into their personal space. Encouraging students to change the background may encourage more to switch on their webcam.

\section{Handling difficult questions}

Understanding your pedagogical approach is vital when you are asked geographical questions, particularly if you don't know the answer! Most often, honesty is the best approach - most students, in most situations, are happy with an answer along the lines of "I don't know, but that's an interesting question, let's find the answer." This sort of reply embodies your role in the classroom, as a facilitator of learning. Practically, it also allows you to broaden your teaching experience, by enabling you to teach classes outside of your specialist research. In contrast, when we do know the answer to a question there is always a danger our answer will be too long, too detailed or pitched at too high a level for our students to comprehend. Keeping in mind Vygotsky's (1978) ideas of 'scaffolding' within the 'zone of proximal development' can be an important part of moderating our answer to best facilitate understanding and learning. 


\section{Reflections on online teaching and learning}

Maddy Thompson (Keele University) is a health geographer, whose research examines transnational forms of healthcare - particularly nurses in the Philippines and migrant carers in the UK. These reflections were co-written with James Flanders, who recently graduated with a $B A$ (hons) degree in geography.

In online seminars, with fewer options for visual communication, there is a need for slower delivery and repetition of key points, building in more breaks to catch your breath/take a drink/ check the technology is still working. Because online communication requires additional time to communicate the content, you have to plan to cover less content in each session. If learners can easily switch between the lecture and external information (websites, videos, quizzes, etc.), then less content needs to be delivered in lecture form. However, learners confined to using a single device will face significant difficulties in switching between programmes, particularly where there is a need for video. Because of this, for smaller group teaching, planning for students to drop out of the call and return at a pre-agreed time can reduce some of these difficulties.

In the case of group work, staff and students can set up chat groups. If staff are invited in, they can view documents students are working on and be added to calls. If staff set up these groups, they can monitor work as it progresses and 'jump in' as if walking around a classroom. Setting clear tasksimproves motivation, and the results of online group work can be very strong! Online group discussions can also be more enriching than turning around in seats or shouting from the back of a lecture hall. But the lower engagement and the different forms of engagement - chat, voice, video - reduce the chance of diverse opinions from entering the teaching space. This creates additional challenges for the teacher as a moderator. It is all too easy to prioritise students that can be seen and heard. There is a need to be reflexive about teaching practices and ensure all voices - no matter how they are expressed are heard. Particularly as students using chat may have issues with anxiety or technology.

Interestingly, many issues lessen in one-to-one video calls. These more personal meetings provide a greater sense of normality and the chance to focus on body language (where video is available) and engage in more natural forms of speaking. Furthermore, there are fewer connectivity issues with fewer people on a call, and - despite their small screens - smartphones can be used more effectively. Students are much more likely to use video in a smaller setting and where they can use smartphones.

Teaching online requires an additional focus on issues of equality, diversity and inclusion. There is a need to switch off from email and video software after working for hours and allow the students to 'switch off' from the call to access files and websites more easily. There is also a need to ensure discussion and group work do not exclude those limited to one device or who prefer not to be seen and heard. This is a difficult task but being reflexive about teaching as part of planning classes is key. 


\section{Dominant voices and keeping control}

Sometimes we need to deflect attention away from the one dominant learner in the class and allow others in the room the opportunity to speak. For example, you could say: "let's go around the room and hear from each group." Alternatively, "that's a really interesting point, let's find out if others agree or disagree with you." Any approach like this is inclusive as you are bringing others into the conversation, which will help the learning of the whole class, including the dominant learners.

Another common scenario is where, as a teacher, you feel you are losing control of a class as lots of unexpected conversations keep breaking out. This can happen in person and online. One solution is to find an inclusive way to reset the conversation, such as by setting a new task or asking a welltimed question, while also reflecting on why this has happened and whether your plan for the class needs to adapt. For example, are the conversations irrelevant, or have you approached your class in a way that is slightly too narrow for issues which are complex and multi-dimensional? Is there something students don't understand, which would benefit from a wider discussion? Are the students working in friendship groups? If they are, they may have discussed many of the issues already when preparing for the class and might benefit from you mixing the groups up to introduce new voices into their learning.

While it is important that learners leave a class with more knowledge than when they entered it, if we focus only on the idea of 'controlling the class', we can stifle learners' ability to construct knowledge and limit our ability to facilitate learning.

\section{Creating effective learning environments when students haven't done the preparatory tasks}

Students in a class often become frustrated with peers who have not done the preparation but then attend classes in order to learn from those who have. One common way to avoid this situation is to collaboratively establish a set of ground rules or expectations with students. This is particularly useful for groups of learners you will teach regularly. For example, an expectation could be that those who attend a seminar have done the preparation and the rule is that those who haven't won't be able to participate until they have completed the preparation. This may involve some students sitting quietly in the class doing the preparatory reading, or, in an online setting, assigning them to a breakout room without other students until they have completed the preparatory tasks. In some classes this approach works, but in others it can become inflammatory as it can look like you are preventing learners from attending and participating particularly if it is out of sync with how other colleagues approach the same situation.

Another, more inclusive, approach is to talk to these learners individually about why they haven't done the preparation - many have complex lives and there could be many reasons for this. Instead of jumping to assumptions, explain that you both need to agree a way for them to maximise their learning in the time available; and that your view is that this will involve them spending the time completing the preparation rather than participating in the class. Put another way, explain that they may not understand parts of the class without having done the preparation first. This sort of approach usually has better outcomes as it treats learners as individuals and puts learning at the centre of the discussion - balancing the fact that there may be good reasons why a learner hasn't done the preparation, with the need to find a way to maximise their learning in the time available, along with the need for all students in the class to maximise their learning as well. It could also be the case that your institution has some rules or guidance on whether students can be prevented from attending class.

\section{Other considerations when developing effective online learning environments}

The approach we have been espousing can be summed up as 'pedagogy before technology'. In other words, that good pedagogy is broadly the same whether teaching online or in person. However, when teaching online there are a few additional things we need to keep in mind, particularly related to digital inclusion (or more accurately, exclusion).

These can include:

- What devices do learners have?

- Do all learners have a good Internet connection?

- What physical spaces are they in?

- Beyond using social media, how digitally literate are they?

- Have they previously learned online? 
Particularly, when students are learning online from home, we shouldn't assume that they will always be in an ideal study space - one that is conducive to the type of learning that they would like or we might expect.

The answers to these sorts of questions will help us to shape an effective learning environment and help us to appreciate how likely it is that learners will engage with the synchronous online learning activities we create (for example, by turning on the webcam on their computer or being able to access a shared document on their phone). The answers to these sorts of questions also help us to appreciate better why this won't always be possible and to put in place, to the extent we can, appropriate accommodations.

\section{How effective is my teaching?}

Feedback and evaluations from our students are a natural part of understanding what works well, how students are getting on and finding areas where we can improve. Whether teaching online or in person there are lots of ways to quickly gather feedback: surveys and polls; asking for feedback via email, in webinars; collecting access data from VLEs; or asking learners to anonymously note down one thing about the class they'd keep, one thing they'd change and one thing they'd like to know more about - this could be done using an online form (examples include SurveyMonkey or Padlet), or in person, or in person using sticky notes. When teaching in person, often the feedback can also be very informal: the expressions on learners' faces, hands going up, comments made and energy shared. Online is different, you can't always quite 'read' learners' reactions or involvement in the same way. Consequently, building simple things into our teaching becomes important - like check-ins, warm-ups, quizzes, a simple thumbs up or down to gauge the level of understanding.

Having gathered feedback from learners, it is also important that as educators we know how to use and react to it. it is important to remember that every class won't go perfectly and that learners may have a diverse range of needs and expectations that are difficult to meet. In essence, when dealing with feedback we need to be kind to ourselves and open to those who learn differently to the way we do. Looking for general trends and themes about what is (and what is not) working well, and which can inform our future teaching, is far more important than fixating on one negative or personally hurtful comment.
Personally hurtful comments have no place in student feedback. If you receive these, talk to the relevant module leader, the Degree Programme Director/Degree Scheme Leader or Head of Geography. Many universities have policies in place to deal with these and offer you support. 


\section{Promoting participation and equality of opportunity in person and online}

\section{Inclusive teaching}

The Higher Education Academy (HEA, 2016: 2) define teaching inclusively as 'recognising all students' entitlement to a learning experience that respects diversity, enables participation, removes barriers and anticipates and considers a variety of learning needs and preferences". Students benefit from learning in an environment where they feel included and where they are taught in ways that recognise and support their needs as individuals, and as part of a learning community. Being inclusive within this context requires us to embrace an increasingly diverse set of student backgrounds and recognise the value of that diversity to our teaching and learning. In the UK the focus of diversity and inclusion is often upon legally protected characteristics (such as age, disability, ethnicity, gender, gender reassignment, religion/belief and sexual orientation). However, there are other dimensions to diversity to which we should also be sensitive in our classroom teaching - such as, the varied backgrounds and experiences of first-generation students.

There are some excellent geographical resources to support inclusive teaching. For example, Annie Hughes and Nona McDuff's chapter in the Handbook for Teaching and Learning in Geography (Walkington, Hill and Dyer, 2019) is an excellent starting point; as is Mary Biddulph's (2017) work on the 'illusion of inclusion' in geography teaching; Robert Wilton's work on geographies of disability (Hall and Wilton, 2017; Marquis et al., 2016); and James Esson's work on decolonising geography (Esson et al., 2017) and teaching about race and racism (Esson and Last, 2019). For more detailed interdisciplinary insights, the Journal of Inclusive Education is another excellent resource.

Clearly, inclusive teaching is a vast topic and it is beyond the scope of this guide to cover it fully. Here, we highlight only three aspects of inclusivity which point to the breadth of the debate. All three examples illustrate that inclusive teaching requires us to focus on 'what' we teach, 'how' we teach it, and the environments we create for student.

\section{Learning styles}

In every class we teach there will be a range of learning styles and each learner will have their own preferred style for learning about geography. For example, whether online or in person, some learners in a class will learn through spoken dialogue more than others and, as we will discuss in more detail in the next chapter, when planning a teaching session we need to think about how we can teach the material in a way that is inclusive to those with different styles of learning.

Avoid falling into the trap of thinking that students who don't talk very often in class aren't learning very much.

There are lots of different typologies which have been developed to try to capture the range of ways in which people learn - each of them heavily critiqued. For example, David Kolb's Taxonomy of Learning Styles (1984; 2015; see also Morris, 2019) identified four types of learners, with four very different sets of strengths and preferences.

Accommodators: 'Hands-on' learners who rely on intuition rather than logic. They prefer to take a practical, experiential approach and are attracted to new challenges and experiences.

Convergers: Good at solving problems and are drawn towards technical tasks and problems than social issues. Students with this learning style like to experiment with new ideas, to simulate and to work in a systematic way.

Divergers: Look at things from different perspectives. They prefer to watch rather than do, to work in groups and to listen with an open mind. They are best at viewing situations from several different viewpoints.

Assimilators: take a logical approach to learning; they are particularly good at understanding wideranging information and organising it in a clear, logical format. They prefer readings, lectures, exploring analytical models and having time to think things through. 
An alternative is the VARK taxonomy of learning styles developed by Fleming and Mills (1992), which shares some similarities and some differences with the ideas of Kolb (1984; 2015).

Visual learners: Prefer ideas to be explained using means other than words - such as graphs, charts, maps, diagrams, videos, etc.

Auditory learners: Acquire knowledge best by listening to lectures, listening to others in discussions or listening to podcasts.

Read/write learners: Prefer words as the means to convey knowledge.

Kinaesthetic learners: Prefer to learn via experience, whether that's fieldtrips, lab experiments or seminar activities.

This isn't to suggest that, as educators, we must subscribe uncritically to one taxonomy or engage with every learning style in every class - that's unrealistic. However, more generally, it is important for us to recognise the diversity of learning preferences amongst our students, to try to provide a range of different activities, and to teach effectively in a range of different ways.

When preparing to teach a class, make a conscious decision to try to provide a range of different activities and to teach in different ways. Avoid planning each class, almost by default, in the way that you preferred to be taught.

\section{Power, identity and emotion}

While debates around learning styles are longstanding and contested, ideas around inclusive teaching extend much further than well-trodden learning style debates. As Carl Bonner-Thompson explores below, as educators we also need to be attentive to the educational, cultural and social backgrounds of our students. We can begin to do this in several ways:

a. By considering our own positionality as an educator (in terms of race, ethnicity, gender, sexual orientation, religion/beliefs, class, etc.) and how this impacts the language and examples we use in our teaching. Do they feel inclusive for everyone? Do we have any unconscious bias?

b. By considering our tone, words and body language and what message these can unintentionally convey to learners about our 'expertise' in the subject.

c. By considering if there are learners who might feel excluded or who are becoming disengaged. Why is this? How can we tell? 


\section{Inclusivity through intersectionality}

Carl Bonner-Thompson (University of Brighton) is a feminist and queer geographer interested in everyday and embodied relationships with digital technology.

When teaching seminars, I try to de-centre myself as an expert or leader to prioritise students' ideas. I see myself as a facilitator in these roles, making sure that the conversation is always moving and developing. I also take my intersectional feminist politics into the classroom. Classrooms are shaped by power, identity and emotion; therefore, I try to be aware of who is being included/ excluded by the content, the modes of teaching (or the hidden curriculum). One way I do this is to encourage students to reflect on their own identities and histories, to become comfortable with their discomforts - I would say this is part of a feminist approach to pedagogy.

I have different ways of doing this - encouraging debate, role-play, group discussions, non-verbal tasks, media that represent multiple cultures, drawings and posters, amongst other methods. For example, I have asked students to create placards as if they were going on a march, which set students up to debate the differences between LGBT and queer politics. I have asked students to reflect on their emotional and embodied experiences of parks, digital technologies, clubs and work. Recently, I have asked students to develop their own questions to the set reading. For example, we might spend the first half of the session discussing a set reading in small groups, but I also ask students to develop a question from their discussion points - this can be conceptual, methodological or a critique. I then rotate the questions, so students answer one anothers'. I find this helps embed student knowledge in the seminar.
Moving this to an increasingly digital format since the Covid-19 pandemic has not been easy - and I would call myself a 'digital geographer'. We all learn how to use digital technologies differently, dependent on our identities, experiences and embodied knowledge, and digital learning environments are spaces in their own right, with particular ways of being that have to be learned. Therefore, offline teaching practices cannot easily be 'transferred' over, especially as students come into these spaces with their own emotions and identities. My usual strategies of encouraging conversation haven't worked as easily, creativity can't be 'done' in the same way and some students don't seem to want to share like they would in a material classroom.

So, what have I done? Well, I have found that students working in small groups to develop their own questions has been useful, using software like OneNote or Whiteboard. I have also found it useful for students to relate the content and concepts to their own lives a valuable tool, especially when teaching first-year students about the concepts of space and place. I think reflexive practice is important - to be able to situate lived experiences and the self in academic work helps bring concepts to life. For example, when introducing students to digital geographies, I asked them to reflect on their own uses of technologies in and through the Covid-19 pandemic and lockdown. This is something I will continue to do, and, as many intersectional feminist academics have argued, will help disrupt dominant forms of teaching, learning and knowledge. 


\section{Anti-racism and decolonisation}

In 2018, James Esson attempted to answer the question: "why is our geography curriculum so white?" The answer, he argued, is coloniality-induced institutional racism, which is best challenged by identifying and using pedagogies that are founded on coexistence and respect, as opposed to domination, separation and assimilation. As educators, we need to remain vigilant to how colonial modes of thinking are reproduced pedagogically in and through curricula content and design. Although, as a teaching assistant or teaching fellow it is unlikely that you will have a formal role in curriculum design, it is still important to think as holistically as possible about the pedagogic approach you take to each class - beyond the more obvious things you can influence, such as the examples or case studies used. While this holistic approach might be imperfect given the limitations of your role, it is important to try to extend lesson planning beyond "add[ing] black thinking to a white pot" (Esson, 2018: 712).

\section{Embedding anti-racism and decolonisation in our teaching}

James Esson (Loughborough University) is a critical development and population geographer. $\mathrm{He}$ is also a member of the RGS-IBG RACE Working Group, engaged with racism issues in higher education.

Decolonisation is not a metaphor. It entails the removal of colonial domination, thereby connecting moves to dismantle racist hierarchies instigated by colonial modernity with indigenous-led demands for the restructuring of land, resources and wealth. So how can you decolonise your learning and teaching? Regardless of your subdiscipline, you will need to begin by asking yourself whether you are fully committed to challenging behaviours and structures that dehumanise, enable inequity and harm nature. If not, it is likely that any efforts to decolonise your learning and teaching will merely amount to a 'move to innocence', i.e., strategies and positionings that aim to relieve those who benefit from coloniality of feelings of guilt or complicity, without having to change their privileged position at all (Tuck and Yang, 2012). If, or hopefully when, you are committed to this challenge, keep reading!

Creating inclusive learning environments informed by a decolonial position requires time and patience. There are no quick-fix solutions to coloniality in the academy (see, for discussion, Daigle and Sundberg, 2017; Domosh, 2015; Mahtani, 2006; Tuck and Yang, 2012). As a starting point, for any module you are teaching, make a conscious effort to 'look at sites closer to home'. Ensure your sessions provide opportunities to "share with our students how gendered and racialised identities influence who is teaching in geography, and why" (Mahtani, 2006: 22). A simple way to do this is by ensuring there is critical reflection on your positionality as well as questioning the sources and examples you are using. Find a moment within your sessions to collectively consider who is being treated as the 'norm' and who is, often by simple structural continuity, being excluded as a legitimate creator of geographical knowledge. This can be done by providing visual representations on slides and handouts of the scholars being cited. Who are we showing as victims, decision-makers, experts, workers? This is relevant not only to race, but also to a range of social differences shaped by coloniality, e.g. gender, (dis)ability, sexuality, etc. An intersectional lens is needed.

You should also aim to contextualise topic material in its historical moment and, where possible, highlight the role of coloniality in shaping the knowledge produced. This critical reflection should lead you to consult a wider range of source materials. This in turn will help you to engage with, and bring to the fore, debates and perspectives outside the Eurocentric academic echo chamber. You can do this even if you have limited control over the module's core reading lists, as there is usually scope to personalise your teaching content. Similarly, while you may not have determined the session format, it will be important to direct the classroom dynamics to proactively disrupt patterns of dominance in discussions. This includes your own behaviour. For example, leave some spaces in the class to acknowledge questions or issues identified by students. Related to this point, if (and they should) students are provided with opportunities to make connections to their existing knowledge and experience, the subjectivities and epistemologies of racially oppressed, indigenous and marginalised groups must be recognised and not devalued. 


\section{Planning and structuring your classes}

Good lesson plans should keep learners focused and on-task and are an essential starting point for creating teaching and learning experiences that will motivate students. Putting student learning at the centre of our lesson plans means we are less likely to fall into the trap of transmitting a lot of information to students without them necessarily having a clear idea of what they're supposed to do with it, or us knowing whether it meets their needs. As a teaching assistant or teaching fellow, it is most likely that you will be asked to deliver synchronous small group teaching, whether in person (in a seminar room, lab, computer room, fieldwork, etc.) or online (this may or may not also be part of a blended or flipped classroom approach). Consequently, planning for small group teaching is the focus of this chapter, but the principles described apply to other forms of teaching too.

\section{Structuring small group work}

Whether teaching online or in person, it is important that small group learning is structured in some way. This helps learners to make sense of the activities and to understand the relationship between the aims or learning outcomes for the class, the teaching that takes place and, ultimately, the assessment the students complete. Meandering discussions that peter out at the end of the class are unlikely to leave a lasting impression on learners. Also, don't forget that your students will arrive at your session from another experience and will need to find a way of settling into the work you are asking of them. Whether teaching online or in person, planning around a structure of introductory activities, followed by main body activities and concluding activities can be helpful. This is the structure we outline further in the rest of the chapter - but, as a reflective teacher, it is for you to adapt it to your individual classes.

\section{Questions to ask a few days before your teaching session with a class to make sure you have everything ready}

These are the questions we need to ask ourselves a few days before each class we teach. Often, we wont know the answer to all of them immediately and so we need to leave sufficient time to find out the answers. Good starting points when looking for answers are the module leader / module convener, or the Degree Programme Director I Degree Scheme Leader, or the professional service staff.

1. Do you have a lesson plan? Do you know what the students have been taught so far/ how your session fits into the overall module design? For example: if you are delivering a seminar, have the students already received a lecture introducing the topic? Do you need to watch this?

2. Do you know where you are going to teach your session? Which building? Or which online platform (e.g. Microsoft Teams, Zoom, Google Meets, etc.)?

3. For in-person teaching, do you know how to get to the venue? Is there a key to collect? Is there a password to access the online meeting?

4. How do you want the room to be set up? If online and you want to use breakout rooms, are you the meeting host so you can arrange these?

5. Will you be co-teaching this session? What is your role?

6. Do you have a register of attendees?

7. Are there any educational needs / student support plans of which you need to be aware?

8. Do you know how all the equipment works? Is there any specialist equipment you need?

9. Are there any specific health and safety precautions for the session?

10. Are you calm, relaxed and ready to greet your students as they arrive in the room or enter the online meeting space? 


\section{Introductory activities}

Introductory activities should ideally be confined to the first 5-10 minutes of a 50-60-minute session, so that students do not feel they are just passing time. It is important to use introductory activities to make the session feel personal (e.g. by helping you to learn some of the students' names) and also in some way tailored to the needs of the group (e.g. making links between one part of the session and later parts, where possible). Some of the following may work well:

Use your introductory activities to assess the class and to adjust your lesson plan accordingly. Even when asked to teach the same class to several different groups, you shouldn't expect to run them all identically.

a. 'What's on top': This is where you ask each student to say what aspect of the module / course is currently most on their mind: the next essay, revision for exams, trying to find a text, etc. This gives you the opportunity to judge the mood of the group and make some small adjustments to your lesson plan.

b. Rounds: This is a versatile technique which can be used at various points in a session, not just the start. For example: as an introduction to see what students expect from the class (e.g. ask each student to finish the sentence "what l'd like to discuss/work on today is..."); to check progress and understanding (ask each student to finish the sentence "where I have got to so far is..."); to take the discussion on (ask each student to finish the sentence "to help me move forward it would be useful to...") or, finally, to conclude the session as a whole (ask each student to finish the sentence "what l've got out of today is..."). Traditionally, rounds are completed orally but they can also be adapted using sticky notes, online discussion boards or apps like Padlet.

\section{Brief clarification of points from any preceding} sessions: This is particularly useful if there has been an earlier lecture on the same topic as your class - often students are reticent about asking questions in a lecture theatre but may be more comfortable asking questions in smaller group teaching environments (seminars, workshops, labs, etc.). There are lots of ways to approach this beyond just asking "anyone have a question?" For example: when teaching in person, you could ask students to write down things they want to address which are then put in a 'hat' (or box). Each student picks out a paper and reads out the question. If teaching online, this can be adapted by using an app like Padlet or Mentimeter or the chat function on Teams or Zoom. They all have. the advantage that students can display uncertainties without undermining their confidence or being exposed, while also opening up conversations early in the session.

\section{d. Name-learning activities, especially if you will be teaching the same group several times:}

As indicated in Chapter 2, pedagogically this is important and the power of using names shouldn't be underestimated: for them to learn effectively, you need students to feel comfortable engaging with each other. Practically, there are lots of icebreaker name-games you can utilise and adapt. One example is 'name chains'. As an online icebreaker, 'two truths and a lie' usually works well. More details about how to play both games are in Chapter 2.

Any time you talk to a student you already know, use their name. For example, saying, "Serhat, did you get the same answer?" makes the class feel more engaged and helps to show students that you care about their individual progression.

\section{Main body of the class - active learning}

Workshops, computer practicals, fieldtrips and labs are easier to structure as they will innately have active learning at their heart and the module leader, or lab technician, will have usually planned this for you to deliver. Often you will be assisting them with the delivery of the class, by answering students' questions one-to-one (see Chapter 5 for a more detailed discussion on delivering practical classes). However, in a traditional seminar, the main activity is sometimes less well-defined by the module leader and can easily end up as a wandering discussion through a pre-set reading that some of the students may not have completed. Below are some alternative activities which you can draw on, to encourage active learning and good discussions, in this sort of seminar situation. Which you choose is often a matter of pragmatism: personal preference, size of the class, how long the class will last, format and layout of the room, etc. However, student-centred learning also advocates allowing students to share in these sorts of decisions. 
Enabling this inclusive approach to teaching might mean delivering the same material in slightly different ways to different groups. This has the added benefit of keeping your interest and energy high when delivering multiple 'repeats' of the same material.

\section{a. Addressing the 'questions in the hat': Here} students can work on the issues that have been raised in the introductory activity. For example, "can we recap the different types of moraines?" in a seminar about glacial landscapes.

b. Buzz groups: These break up large groups into smaller ones and, used judiciously, can often produce stimulating ideas. The groups may all be working on the same material (case study, article, set of questions, problems to address) or different groups may be given different activities. Groups report back their ideas to the rest of the class for discussion.

c. Pyramids/Snowballs: The aim here is to start students off in a small group (e.g. a pair), then to build on this in a mid-sized group (4-6 students), before finally reporting to a plenary session.

d. Syndicates: These are teams of students working in parallel on the same task, usually a problem or a case study. The teacher sets up the task and provides the resources. At the end, the teams of students report to the group.

e. Debates: Students can be formally organised into debating teams and asked to present cases and counter-cases and deal with questions from the 'floor'. This can be extremely useful for looking at two sides of an argument and developing students' critical thinking, but it also needs active management to secure wide involvement. There are also some EDI and wellbeing issues associated with compelling all students to speak in public, so asking the class to elect a rapporteur for each side of the debate is often the best approach. Learners with anxiety or neurodiversity conditions, for example, will find using a rapporteur a more inclusive approach to debating.

f. Think-pair-share: Pose an open-ended question to the class and ask students to independently compose their 'best' answer. The students then pair up and share their responses - this could be done in person or online in a breakout room. The pair of students then join another pair to further improve the response. This format continues until you have two large groups going head-to-head to discuss their responses.

g. Self-Organised Learning Environment (SOLE): While all of the above activities can be made to work well online and in person, SOLE is particularly suited to online environments (where you are sure learners have access to a PC or phone) and when you are using a form of technology for the class that facilitates breakout groups. In a SOLE class, your role is to encourage learners to work as a community and to answer questions using the internet. In practical terms, SOLE classes work around a guiding set of rules: (a) students need to form groups of about four; they can change groups at any time; (b) students can look to see what other groups are doing and take that information back to their own group; (c) students should be ready to present their answers back to the class at the end of the session; (d) large, open, difficult and interesting questions often make the best questions for a SOLE session - they encourage students to use Bloom's high-order thinking skills, to engage for longer and promote deeper conversations amongst groups and peers. If you are setting an enquiry question around a topic already taught in a lecture, it can be helpful to ask a question slightly removed from the specifics of the lecture. A question that refers to the 'big picture' (or so-called 'wickedproblems') can often yield more interesting results. A wicked problem is an issue or concern that is difficult to explain or solve. Examples of wicked problems include things like financial crises, health care, hunger, poverty, terrorism, and sustainability.

It is likely that some students in any class you teach will have either mental health challenges, a disability (this might be a hidden disability) or specific learning needs. In most instances module leaders / module conveners are notified about these at the start of the academic year and given advice on the support needed to help the students to maximise their potential. For every module you teach, ask the module leader whether they are able to share this information with you. Also discuss with them how to accommodate, in an inclusive way, the support these students need within your lesson plan. 


\section{Main body of the class - questioning}

There are many ways to approach asking questions to encourage good discussion and you may want to experiment with different approaches. It is possible to use questions badly: asking too many questions, asking several questions at once, asking confusing questions, not allowing learners time to think. It is important to plan how you will use questions so that you bring out the best in the students. The following suggestions might help.

a. Use questions which scaffold learners' discussions up to greater levels of sophistication: Bloom's taxonomy (Chapter 1) can be used as one approach to scaffold questions from the very simple (describe) to the more complex (evaluate).

b. Socratic questioning: Socrates suggested specific types of questions to elicit a range of responses. This model is used in the training of barristers in the UK and in educational contexts in many parts of the world. This model covers six types of questions. Let's look at an example of each in the context of a hypothetical class about Edward Said's idea of Orientalism.

\begin{tabular}{|l|l|}
\hline Type of question & Example \\
\hline $\begin{array}{l}\text { That looks to clarify key } \\
\text { points }\end{array}$ & $\begin{array}{l}\text { How does Said define } \\
\text { Orientalism? }\end{array}$ \\
\hline That probes assumptions & $\begin{array}{l}\text { How do you define East and } \\
\text { West? Is this the same as } \\
\text { Said? }\end{array}$ \\
\hline $\begin{array}{l}\text { That enquires into } \\
\text { viewpoints or perspectives }\end{array}$ & $\begin{array}{l}\text { What is the influence of your } \\
\text { own positionality upon your } \\
\text { view of Said's ideas? }\end{array}$ \\
\hline $\begin{array}{l}\text { That probes implications } \\
\text { and consequences }\end{array}$ & $\begin{array}{l}\text { What are the } \\
\text { consequences of reflecting } \\
\text { upon your positionality for } \\
\text { the argument you are trying } \\
\text { to make about Orientalism? }\end{array}$ \\
\hline $\begin{array}{l}\text { That probes reasons and } \\
\text { evidence }\end{array}$ & $\begin{array}{l}\text { What evidence is there to } \\
\text { support your view that Said } \\
\text { misunderstands the nature } \\
\text { of British Orientalism in } \\
\text { India? }\end{array}$ \\
\hline
\end{tabular}

\section{Closing activity}

It is important that the learning of students is captured in some way. Where several groups are reporting back on activities, there is often a loss of energy and learners may not listen well to each other. The following suggestions are ways of helping learners to capture their learning:

a. A closing round of 'the key things I learned from today were...' or 'the issue I want to follow up from this discussion is...'

b. Ask learners to summarise the key points from the discussion.

c. A volunteer keeps notes during the whole class and writes these up to go on the module's VLE, or distributes them in some other way (e.g. email).

d. Students produce flip charts of key points. When teaching online, these can be replaced by using an app like Padlet boards or Mentimeter word clouds.

e. You summarise what the group has achieved in the session.

f. You discuss the preparation necessary for the next session.

\section{Planning classes and developing teaching materials in an accessible way}

When planning any teaching activity, we need to consider any disabilities, physical or sensory impairments our students may have by preparing accessible content. We also need to be mindful (particularly when teaching online) that it is unlikely all our students will have the same level of access to computers and other digital technologies. Consequently, all new teaching material should be created with the question "how can I ensure this is accessible?" in mind. Our starting point should be to ask the module leader / module convener for any information they have about the needs of individual students (such as student support plans). However, there are also generic steps we should take before every class to improve the accessibly of our teaching. These steps include: trying to design classes around standard office software and other open-access software that can run on standard PCs, with average wi-fi speeds; avoiding lesson plans that require students to be able to download bespoke apps (they might not have a mobile phone, or a contract with unlimited data); and to produce one version of 
resources that everyone can adapt to their own needs. This could be as simple as providing your material as an editable word processing document (which can be reformatted or used with a screen reader) rather than a PDF that cannot be edited. If this isn't possible, we need to know how we can provide the same information for a comparable experience.

Make all electronic teaching resources available in an editable format as this makes it easier for learners to adapt them to their own preferences. Make them available (e.g. via the VLE) in advance of your session.

Rather than assuming that this isn't needed for those in your class, we need to think broadly. Many disabilities and impairments are hidden, and anybody can become 'situationally disabled': for example, if learners are in a public location and don't have headphones, they won't be able to listen to a lecture easily but could read the captions. Likewise, if learners are forced to view a VLE on a small mobile phone, they'll appreciate the ability to make the text larger. The following principles may help when creating any teaching resources:

\section{a. Colour}

Avoid the use of colour as the only way to convey meaning (e.g. red text for important statements). Always use a combination of colour, shapes and text to convey meaning.

\section{b. Alignment}

Always use left-aligned text, 1.5 line spacing and a suitable font size - usually $12 \mathrm{pt}$ for Microsoft Word and 22-26pt for PowerPoint.

Avoid centre and right alignment of text or full justification on both sides of the page.

\section{c. Layout}

Always break up information with meaningful headings, sub-headings and one-level bullet lists. To make it easier for screen reading technology to read your documents, use a logical heading order and the built-in header formatting tools in Word.

\section{d. Styles}

Always write headings in sentence case - AVOID CAPITAL LETTERS.

Avoid the use of text size, all capital letters and layout as the only way to convey structure.

\section{e. Media}

Always add meaningful alternative (alt) text to images, and captions and transcripts for videos. Avoid the use of rich media content without providing a text alternative.

\section{f. Fonts}

Always use a sans-serif font, such as Tahoma, Arial, Verdana or Calibri.

Always use a readable font with sufficient colour contrast from the background.

Avoid low colour contrasts, small font sizes and cursive or script fonts.

Avoid white writing on a dark background. If using PowerPoint, dark text on a pastel background works best (e.g. dark blue text on a cream background).

\section{g. Emphasis}

Always make important information clear and easy to find.

Avoid underlined words, italics and all capital letters - use bold for emphasis instead.

\section{h. Inputs}

Always ensure all content can be navigated with a keyboard (using a mouse or touch screen doesn't suit everyone).

\section{i. Contrast}

Always use a textbox to increase contrast between images and text.

Avoid text over images or patterned backgrounds.

\section{j. Video and audio}

Always allow user control and navigation of all video and audio content.

Avoid the automatic start of any audio or video content.

Make captions or a transcript available.

While many universities provide their own guides on producing accessible materials, Microsoft also have some useful tips and resources for creating accessible resources on their webpages. For example, Microsoft Office now includes inbuilt tools to support the creation of accessible documents. 
When we think about practical teaching in human or physical geography, most often we think about fieldwork (whether daytrips or residential, in familiar or unfamiliar locations). Fieldwork is integral to all geography degree programmes. It provides geographers with an opportunity for experiential active learning (learning by doing) that inspires students' engagement with the subject. It reflects that realworld learning and context-based applied learning are fundamental to understanding, and changing, our world. For these reasons, and as discussed in Chapter 1 , fieldwork is a signature pedagogy in geography. However, human and physical geographers employ an expansive understanding of the 'field' and require access to a variety of types of 'fields' in order to meet programme learning outcomes. For example, they require access to particular landscapes, ecosystems, urban environments, archives, digital spaces, etc. We shouldn't define fieldwork too narrowly.

Increasingly, employers are looking for graduates who can show more than just degree-specific abilities. Instead, they also want to see graduates with welldeveloped transferable skills. Practical teaching in both the field and lab is important because it gives learners opportunities to develop key employability skills through using industry standard software or lab protocols, while also affording learners the opportunity to develop key transferable skills, such as: teamwork; problem-solving learning; research design, planning and implementation; data collection, management and analysis; resilience, flexibility and coping with uncertainty and unfamiliar situations; and understanding and managing risks. It is also a key means of delivery for specific skills that cannot readily be obtained in the classroom (observation and interpretation, experiential learning, understanding cultures, landscapes and places through lived experience, etc.). Field and lab work give students experience and critical understanding of the link between the real world and measurement as captured in spatial data and place-based representations.

While many geography students will have done some fieldwork at school, most new geography undergraduates are unlikely to have been in remote places; been in a chemistry or geomorphology lab; or used GIS and statistical software in a computer lab. Some of the techniques and machines can sound incredibly intimidating to undergraduates (highpressure liquid chromatography, gas chromatography, mass spectrometry, etc.) and make use of expensive software. Consequently, there is a balance to strike in our approach to practical teaching - the classes should be challenging and the learning deep, but we should not expect too much of undergraduate students too soon and we need to support them in their learning.

Be aware that you will have a range of abilities and motivations for fieldwork within a student cohort. Most won't have extensive experience of field- or lab-based learning, so try to empathise with the new situation in which they find themselves.

\section{What are the roles of a demonstrator?}

You might imagine that your role as a demonstrator is just that - teaching and demonstrating. However, practical teaching often takes place over a longer period of time than other forms of teaching and so allows for an intensive, immersive process in which learners can undertake a concentrated period of study uninterrupted by other commitments. This communal experience facilitates the breakdown of barriers between staff and students, and between students and their peers. In particular, social interaction during field courses enhances student learning because - as we saw in the work of Maslow in Chapter 2 - they realise staff are approachable and this facilitates students to become more proactive in the learning process. This creates both opportunities and challenges for demonstrators. On the one hand, an important part of practical teaching is the way it encourages learners to think deeply, critically or evaluatively about what they are learning. Students are moved from surface learning to deep learning because practical teaching involves problem-solving or working through a series of actions in order to generate data. It epitomises experiential learning by doing. On the other hand, the immersive environment means that demonstrators may be asked 
(or may need) to juggle several roles at the same time: to be an observer or commentator on student presentations, to monitor a drop-in session, or to be a trouble-shooter for learners using a piece of equipment for the first time.

As practical teaching often involves groupwork, sometimes students will see demonstrators as counsellors or mediators in their peer-to-peer disputes or will ask them to clarify what they have just been told by the module leader. Demonstrators will also most likely be asked to undertake assessments and evaluate student work, usually at the early stages of their degree programme.

There are many different types of practical teaching. As a demonstrator you will most likely be involved in $\mathrm{A}-\mathrm{C}$ from the list below, but there is a chance you will also get asked to be involved in $\mathrm{D}$ and $\mathrm{E}$.

A Demonstration: technique is shown.

B Exercise: recipe card instruction.

C Structured enquiry (problem based learning): learners select methods/materials.

D Open-ended enquiry: learners determine/ design experimental procedures.

E Project: student-led or lecturer-defined enquiry.

Figure 6: Examples of practical teaching

\section{What skills do graduate demonstrators need?}

As we alluded to above, demonstrators are often an approachable, 'friendly face'. They need to be encouraging but they must avoid doing the work for their students (they will ask). Demonstrators also need to be proactive in running sessions and in ensuring they know exactly what is required by the module organiser. This tallies with the need to be well-prepared, as learners very quickly see-through attempts to 'wing it', making up the next steps as the class progresses. When it comes to running or assisting with a session, it is helpful to be attuned to listening to learners and determining very quickly what their main point or main problem is (this really helps if you need to go through and explain a concept or process again).
Do not talk too much! As a demonstrator there is the temptation to over explain or effectively tell the students exactly what to do. Instead, try to tease the information out of the learners by posing questions back to them to enable them to reach the answer they are looking for. Students will ask you straight up for the answer, but they will learn more if you don't give it to them!

Subject-specific skills and subject knowledge are also important - but never be afraid to say you do not know the answer to a question. It is better to be honest. If you are demonstrating a session alongside the module organiser, you can defer to them for the answer. Alternatively, you can flip a question on its head by asking the learners questions to see if they can figure out the problem for themselves. As Chapter 1 explored, Social Constructivism requires us to be facilitators of learning and effective demonstrators use scaffolding to support student learning. Scaffolding could be in the form of questions around the task that help the learners link the task with theory. It could be simply making linkages between the task and how it builds upon skills they have developed in another module or previous study. Aligned to both questioning and scaffolding, demonstrators also use prompting to promote learning. For example, a well-timed prompt can encourage learners to make linkages for themselves about how the task enables a better understanding of theoretical concepts or ideas covered in other modules. Never underestimate your capacity to promote better understanding by simply getting the learners to talk it out themselves.

\section{Inclusive and accessible teaching in the field and lab}

During 2020, the Council of Heads of Geography in UK Higher Education Institutions (CHGHEI) unanimously agreed five principles that should guide us in the planning and delivery of the fieldwork provision for all undergraduate geographers (RGS-IBG, 2020a). All learners have the potential to do well in their geography degree, even though many will arrive at university with neurodiversity, various physical and mental health conditions or with a disability already diagnosed. Keeping this in mind, fieldwork should be fair and appropriate and, to the extent possible, overcome possible costs and other factors that might impact a learner's ability to participate (gender, sexuality, caring responsibilities, etc.). Consequently, as we discussed in chapters 2 and 3 , when preparing to 
teach we need to ensure that our pedagogic approach and our teaching are inclusive and accessible.

Inclusive teaching recognises that all learners are entitled to a learning experience that respects diversity and enables participation by removing barriers. This applies to all teaching, but practical teaching can introduce new scenarios for which we need to plan effectively.

In geography we are fortunate to have a rich set of resources to help us embed EDI within the delivery of fieldwork and practicals. For example, a wide range of up-to-date resources are hosted on the RGS-IBG webpages (2021). Anson MacKay's blog, entitled 'Out in the Field' and posted on the Geography Directions website, provides an insightful first-hand account of the barriers to fieldwork encountered by members of the LGBTQI+ community (Mackay, 2020). It also provides a list of practical steps we can all take to make fieldwork more inclusive. While some of these are the responsibility of Degree Programme Directors / Degree Scheme Leaders or module leaders, we all have a part to play in establishing a policy of zero tolerance for any form of harassment and bullying. To support this, it is useful for non-LGBTQI+ demonstrators to ask whether funding is available for 'Allies' training or similar (Stonewall, 2021).

To take another example, Hall, Healey and Harrison (2007) use their article in the Journal of Geography in Higher Education to challenge the ableist assumptions that have historically underpinned geography fieldwork. Their survey of staff providing learning support to disabled students to disabled students undertaking geography fieldwork is also a useful benchmark in supporting visible and invisible disabilities.

Planning and preparation are vital to the success of practical teaching. Before any practical classes or fieldwork, ask the module leader or session organiser for a copy of the risk assessment, student support plans and the kit list. In addition, some module leaders may be able to provide an inclusivity impact assessment, ethics assessment and carbon audit for any travel involved. Also, ask what training is needed and available and whether a recce / site visit is needed before the fieldwork begins.

\section{Staying safe in the field and lab}

While practical teaching can be really good fun, one area that is taken very seriously by all universities is health and safety. Many of the health and safety systems universities have in place can initially appear invisible to students and demonstrators - but it is important that you know they are there. As a minimum, ask the module leader or session organiser for a safety briefing and a copy of the risk assessment before a fieldtrip or other practical class. You should also ask whether an inclusivity impact assessment has been undertaken on the fieldwork and if you can see the results. Although different universities have different rules regarding informing demonstrators about the individual needs of learners before the session begins, it is worth asking the module leader if there are any specific student needs of which you should be aware. Finally, if your university offers more formal training in health and safety, including first aid and mental health first aid, it is also a good idea to undertake this - the stress of being in unfamiliar environments during fieldwork can result in mental health and wellbeing conditions manifesting themselves while students are in the field.

If you have any concerns about the mental health or wellbeing of a student, let the field trip leader know immediately. As part of your professional development, you should also review some of the resources available to help university staff to understand and address mental health and wellbeing issues in higher education. Some of these particularly deal with specific challenges that may arise within geography programmes, such as during fieldwork. They can be accessed from the RGS (with IBG) website.

\section{Ethics, positionality and reflexivity in the field}

A major theme within human geography fieldwork relates to the methodological and philosophical issues of positionality and reflexivity. Consideration of these issues began with feminist and postcolonial geographers who interrogated the ethics and politics of field practices and the relationships they create. Their critiques have laid the foundations for more generally reflexive fieldtrips, which are opportunities to reflect on sensibilities, such as the positionalities, responsibilities and relationalities of students and staff. Consequently, 
all fieldwork should be planned and conducted in a way that is ethical, responsible, careful and safe, for students, staff, visited communities and all other stakeholders. To facilitate this, an ethics assessment is sometimes undertaken by module leaders or fieldtrip leaders prior to undergraduate fieldwork. You should talk to the module leader or fieldtrip leader about these issues before the fieldwork starts, as an important part of being a demonstrator is to ensure learners consider their positionality at every stage of the fieldwork process. Michael Glass' essay on critical reflexivity, in fieldwork in the Journal of Geography in Higher Education (2015), is excellent at explaining how instructors and students can become more attentive to their field experiences and the skills they are developing along the way.

\section{Sustainability and fieldwork}

An important part of the process of reflection is supporting learners to be more attentive to the sustainability and carbon footprint of our fieldwork. Recognising that fieldwork is integral to geographical education and that this will commonly involve travel, we must support learners to think through and weigh up the environmental costs involved with the geographical learning against the transferable skills, development of social and cultural capital and other educational benefits developed through learning within specific environments. Integral to this is encouraging learners to engage with debates around carbon offsetting, low-carbon travel and the opportunities for virtual fieldwork. More practically, it is about helping learners to understand that doing geographical fieldwork is a privilege and that making the most of the learning opportunity it provides is an important part of balancing the costs.

Be aware that learners have a range of abilities, backgrounds and past experiences. Many are not that comfortable in an unfamiliar environment/terrain.

\section{Responding to problems}

From time to time things go wrong during practical teaching. Luckily, serious problems are rare, and these will always be dealt with by the module leader or member of staff leading the session. If you see or hear anything of concern, contact the module leader or fieldwork leader straight away. However, you may need to intervene to try to resolve more minor problems as they occur. Often these are borne out of frustration when learners find a task difficult, when they are taken out of their comfort zone or when personalities clash during groupwork. Let's look at some examples. While there is often no one right way to deal with each, they illustrate that patience, adaptability and flexibility are the keys to success in practical teaching.

a. Dealing with practical exercises that go wrong: Resist the urge to panic if things go wrong; it happens to everyone and you can no doubt recall mishaps when you were a student. Try to explore with a group or student why things have failed; check instructions have been followed; check whether you have forgotten to mention a crucial point; find out whether it is an isolated incident or whether others are having trouble. If there is a problem with the whole class, the staff member in charge should be called in to review the situation. It could even be an opportunity to engage in some problem solving. If the equipment has broken down or failed, you should call the technician and not try to mend it yourself. In the meantime, the students affected could join with another group, if appropriate.

b. Dealing with a student who is not pulling their weight in a group: Talk to the whole group about what they are working on. Try to involve everyone in the discussion and ask the less-than-involved students for their views and to outline their part in the proceedings. Re-check support plans to see if there is any reason the student might find groupwork difficult. It may be necessary to allocate changed tasks within the group to engage the students with the work.

c. Dealing with arguments between students: It is best not to get drawn into such arguments; rather, be alert to the possibility of tensions developing and move swiftly to defuse things. Focusing on the task in hand rather than on the dispute and trying to get the students to re-engage with the material with comments designed to encourage or direct them should help. 


\section{Virtual fieldwork: not just for pandemics}

Des McDougall (University of Worcester) is a physical geographer with interests in glaciers and glaciation, mountain geomorphology and Quaternary environmental change. His pedagogic interests lie in learning technologies, fieldwork and virtual reality.

Virtual fieldtrips can create opportunities for oncampus teaching and assessment that would not otherwise be possible; and support real fieldwork. The extent to which these can be realised varies because virtual fieldtrips embrace such a wide range of technical and pedagogic approaches. This greatly complicates any attempt to offer tips and advice for using virtual fieldtrips in teaching!

The following examples are based on immersive, ground-level virtual fieldtrips. These provide a closer approximation to being in the field than, say, a Google Earth fly-through. A virtual fieldtrip using Google Street View would be a good example of this. Another is provided by VR Glaciers and Glaciated Landscapes (vrglaciers. wp.worc.ac.uk), where - just like Google Street View - the virtual fieldtrips lack any embedded interpretation. There are pros and cons to the latter, but it provides maximum pedagogic flexibility and is easier to develop.
Examples of how virtual fieldtrips can be used to support student learning:

a. Applying what has just been learned. Following a lecture or seminar, students can instantly travel to one or more remote location to apply and extend their understanding. The activities may take the form of worksheets, group presentations or mapping exercises. Your role would be to support students to complete the tasks as part of sessions in the computer labs.

b. Developing spatial literacy skills. A sideby-side comparison of ground-level and satellite views can help develop landform and landscape interpretation skills, including raising awareness of scale and perspective issues. Activities can include the use of GIS software (e.g. ArcGIS Pro, Google Earth).

c. Assessment. Students can use virtual fieldtrips as a basis for assessment. Examples include mapping projects, field guides (e.g. to geomorphology), sustainability assessments and hazard evaluations.

d. Supporting real fieldwork. Virtual fieldwork can be used as preparation and a follow-up and to fieldwork that physically takes place in the field

As with anything, virtual fieldtrips have their limitations. For example, they are unable to replicate the totality of the student field experience - which is about so much more than learning outcomes. In addition, virtual fieldtrips are not a sticking plaster for the EDI and accessibility issues associated with physical fieldwork. 


\section{Assessment and feedback}

\section{What makes feedback effective?}

Effective feedback can take many forms and can be informal or formal in style. For example, it can be the words written in the margin of an assessment or on a feedback proforma; the informal, generic feedback provided to a class after group presentations on a fieldtrip; or discussing with a student how they produced their GIS map during a computer practical.

Regardless of the mode of delivery, effective feedback identifies strengths and weaknesses and provides clear guidance on how future performance can be improved. It balances comprehensiveness and quality assurance (such as justifying the mark), with also being inspirational, encouraging and providing learners with clear steps for how to do better. Providing only ticks, question marks and vague comments (such as "keep up the good work") in the margin of assessments rarely makes feedback effective.

In 2013 the HEA designed a feedback toolkit, which placed students' learning at the centre of effective feedback. It identified feedback as being effective if it:

- is picked up, read and acted on by learners

- is timely

- helps learners take action to improve their learning

- is clear, detailed and specific

- has a forward-facing focus

- builds motivation and self-esteem

- is realistic and focuses on learners' performance

- is targeted to the purpose of the assignment and the criteria for success

- encourages learners to have dialogue with tutors and peers to make sense of their learning

- helps learners develop their ability to make informed judgements on their own work (HEA, 2013)

Consider starting and finishing your feedback with positive comments. In between these, provide constructive points for improvement going forward. Avoid too many negative comments about what the student did wrong!
While not all of these may be practicable within a specific context or situation, learners are astute enough to recognise what makes feedback more, or less, effective. We spend a lot of time and effort on feedback and so, as educators, it makes sense to listen to students' views on what they value in feedback, and what they find less helpful. For example, Irons (2007) found that students can be demotivated when they perceive the feedback to be unfair; when the comments don't seem to match the mark awarded; when they don't understand the feedback or the handwriting isn't legible; when the feedback doesn't seem to relate to the work they have done; when they don't receive feedback in time; when the feedback is overly critical and it isn't constructive.

Although a lot of feedback is now provided online (using, for example, GradeMark in Turnitin or SpeedGrader in Canvas), if you are providing handwritten feedback on scripts, two golden rules apply: make sure your handwriting remains legible on every script and don't use a red pen! Red ink has such negative connotations (usually associated with schoolteachers' marking) that it is best to avoid it.

Before you start marking, check your department's policy on how to mark assessments written by students with specific learning differences (SpLD), such as dyslexia. For example, is their policy to ignore spelling and grammatical errors from these students, or not? If marking anonymously, how does the department identify assessments submitted by dyslexic students? 


\section{Formative and summative feedback}

Effective feedback falls into one of two categories and it is important to know which you are providing. Formative feedback provides learners with an opportunity to appreciate better how they are doing (put another way, it is assessment for learning). It can be formal or informal in style and usually does not involve awarding a mark. In contrast, summative feedback provides a formal opportunity to appraise how learners are doing. In other words, it is the assessment of learning and nearly always involves awarding a mark.

Effective formative feedback usually has a forwardfacing focus. It can be conceptualised as feeding forward and as action-orientated on what a learner can change to improve their performance in the future. Effective summative feedback should also demonstrate these qualities, but it also needs to contain a clear justification for the mark awarded. Helpful phrases for justifying your mark can usually be found in the mark scheme (also known as the marking criteria, assessment criteria, rubric, marking grid etc). For example, phrases in mark schemes such as "largely descriptive", "critical and evaluative tone", or "some comprehension of the facts" all point strongly towards the mark awarded. We talk more about this in the section of this chapter called "Getting started with marking". For now, let us just note that justifying the mark in summative feedback does not mean we should several copy sentences out of the marking scheme, as that will make our feedback seem too impersonal or generic when our students receive it. 
(a) An example of formulaic feedback on a geography dissertation research proposal. Note the generic style and lack of feed-forward advice. Note also the strong link to phrases from the marking criteria, which helps to justify the mark awarded (in many marking criteria 'good' is associated with a mark in the 50s).

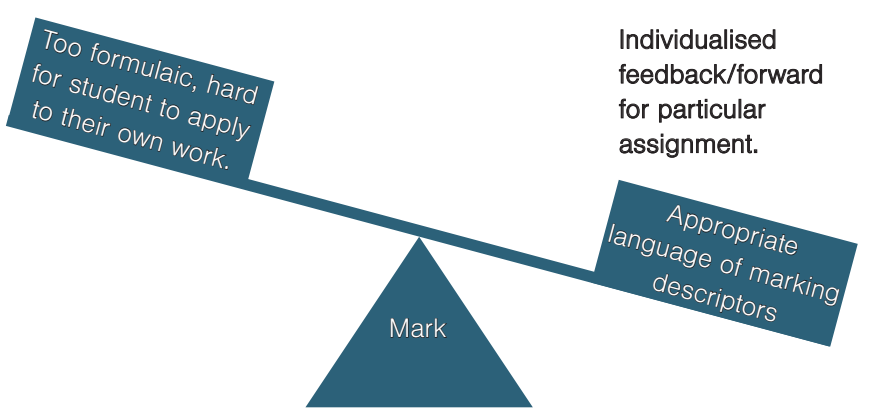

Additional comments:

- good description of the topic

- good identification of the theoretical background

- good research design/method

(b) Another example of feedback on a geography dissertation research proposal. Note the customised feedforward advice, bookended by positive comments before and after. Note also the weaker relationship between the comments and the marking criteria:

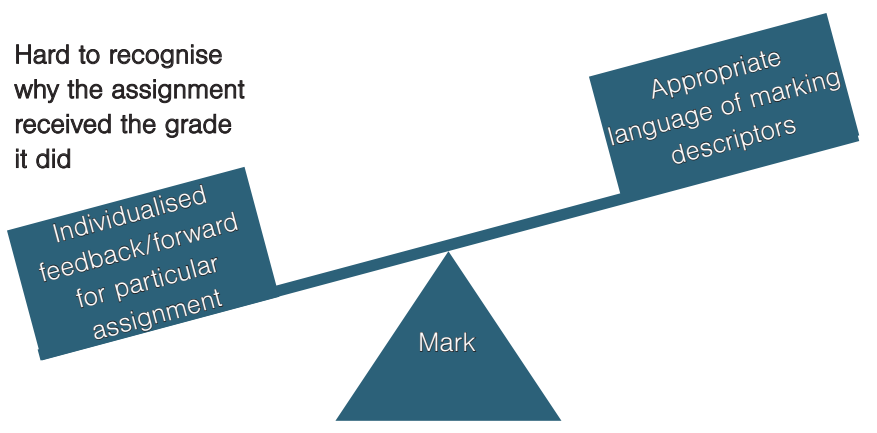

Additional comments:

Overall this was a very interesting dissertation proposal presentation.

It was to your credit that you didn't read directly from a script. This helped you to engage with the andience better and also allowed you to show that you understand the issues at a deeper level - your body language was positive. The pace of your delivery was correct and you managed to balance effectively your enthusiasm for the topic with not peaking too quickly. However, seated at the back of the room you sounded a little quiet and I couldn't catch every word. I like your almost conversational style of presenting but remember to still project your voice.

In terms of some questions for you to think about: do you use the term Irish identity to mean the Republic of Ireland? What about Northern Irish cultural and national identify? Is authenticity a key issue for you to look at? Can you really do effective ethnography in such a small timescale?

Slides were very clear throughout. Timing was good and questions were handled well. Well done.

(c) Effective feedback means getting the balance between the two just right: 


\section{Getting started with marking}

One of the most difficult aspects of marking assessments is knowing what constitutes a first-, second- or third-class piece of work. To start figuring this out, look at your department's marking scheme (also known as the marking criteria, assessment criteria, rubric, marking grid etc). While some are quite granular in detail, this should at least set out the criteria for awarding marks in the 40s, 50s, 60s, 70 s, etc. Most universities mark in percentages (though a few use categorical marking) so ensuring you are familiar with the marking scheme is the first stage in the marking process. Secondly, find out if there is a departmental marking proforma for different assessment types (essays, reports, oral presentations, etc.), as these also tend to set out the criteria against which the assessment is being marked and provide qualitative descriptors in each of the mark categories. Finally, ensure you have a discussion with the module organiser about what it is they are looking for in the assessment and ask if they have some examples of (anonymised) past student work that you can look at. Alternatively, ask if they will jointly mark the first few assessments with you. This will give you a benchmark as to what they expect from learners, which you can then use to mark the remaining assessments.

When marking large numbers of the same assessment, sometimes our grading changes and we inadvertently mark more generously (or harshly) than when we began. It is important to recognise this, and to understand it can happen to anyone. A good test is to check if the batch of marking has a roughly normal distribution, with relatively few high or low marks awarded. If it hasn't, don't panic; revisit the scripts and, if needed, adjust some of the marks.

\section{Developing learners' assessment literacy}

Assessment literacy is the capacity of learners to make better sense of their mark and feedback and, armed with this improved understanding, to exercise more control over their learning. Strategies that require learners to actively engage with assessments will result in deeper and longer-term development of assessment literacy (Price et al., 2012). This can be achieved in many ways. For example, if you are asked to deliver an assessment workshop or seminar, you could ask learners to identify common themes in the feedback they have received previously. Actively encouraging learners to reflect on and be reflexive towards their feedback can help them identify areas for improvement and begin the process of developing assessment literacy. This process also helps us, as markers, to better understand what learners (mis)interpret and take forward from our feedback comments. Alternatively, ask the module leader to provide you with some assessment exemplars and then ask learners to attempt to mark them and provide feedback. In turn, this should help to facilitate a discussion about assessment expectations and the meaning of the assessment marking criteria.

When communicating with students, it is important not to get too caught up in a conversation about their mark, especially where a student is unhappy with it. Instead, try to focus on having feedforward discussions about what they can change to improve in their future assessments.

\section{The feedback 'gap'}

Modularisation is sometimes seen as compartmentalising learning by students (Hughes et al., 2015) and consequently learning and feedback in one module might seem irrelevant to that of another. Evans (2013) calls this the 'feedback gap'. However, well-written summative feedback can be part of a trans-module process of developing our learners: for example, by providing a mixture of bespoke and generic feed-forward comments and by developing their assessment literacy (Price et al., 2012). Linking assessment tasks to module or programme learning outcomes can also help learners to see how each assessment has rea real applicability to future assessments and degree outcomes. 


\section{Marking assessments when you aren't an expert in the field}

Often, we are asked (or required!) to mark assessments outside of our own area of expertise or types of assessment with which we are less familiar. This particularly happens when marking assessments for first-year modules, which tend to have a broader focus than the increasingly research-led modules in second- and third-year. In this situation, we might not feel qualified to give feedback. While there will always be some assessments which are too far out of our comfort zone for us to feel we can mark them effectively, by applying the principles from this chapter we can provide helpful feedback to learners on a broader range of assessments than we might first imagine. This might include advising on:

- the clarity of the argument;

- the writing style (past vs present tense; passive or active voice; personal pronouns or third person);

- the extent to which the assessment is descriptive, rather than critical or evaluative;

- whether the structure of the assessment is logical and easy to follow;

- the presentation and format of tables and figures;

- the use of literature to support points and quality of referencing.

Providing this sort of feedback is helpful to the learners, particularly if written in a feed-forward style. It also avoids us being drawn into a "what's the right answer?" discussion with learners, freeing us from the need to be very familiar with the literature on a topic that isn't the focus of our PhD.

In addition, the module organiser will often have model answers for assessments. This can certainly make marking unfamiliar topics/subjects easier no matter the assessment type. Many universities also have well-designed feedback and marking grids for different assessment types. Using these, alongside having a conversation with the module organiser about what they expect from the assessment, can leave you better prepared to undertake the marking task. Never be afraid to ask the module organiser to double check (moderate) the first few assessments you mark as this can save a lot of time in the long run.

\section{Time for marking}

As we become more experienced, and our confidence increases, we become more efficient and effective markers, but it still takes time no matter how long you have been in academia! That said, it is important to remember that with feedback 'less is often more'. The purpose of providing feedback is to enable learners to see for themselves where they are getting it right but also where they can improve. Providing learners with a few key points they can action is better than returning an assessment with a long 'to-do list'. Also, remember that as markers we are not proof-readers or copy editors. It is helpful for learners to know if an aspect of their grammar or spelling needs to improve, or if there are too many typos in the assessment - but there is no expectation that we will make every correction as we read the assessment.

There is always an external verification process of marked work. This may be the module organiser or another member of staff in the department. The role of the verifier or moderator is to determine if the marking has been fair and consistent across the cohort (usually they do not adjust individual marks). 


\section{Professional development and learning from others}

At all stages of your teaching career, it can be very helpful to learn from the work of others and share your own reflections with others. Within geography, several networks, groups and publications exist to help facilitate this. Getting involved with these activities can be a great way to learn new ideas, be inspired by current issues and discussions, and develop professionally throughout your career.

Engaging with the Royal Geographical Society (with IBG) is a great way to get involved in current discussions and activities across geography. The Society has 32 research and working groups, which bring together active researchers and those with a professional interest in a particular aspect of geography and related disciplines. Many of them engage with teaching and learning issues relevant to their specialism and have their own web resources, mailing lists and events, which may be helpful when teaching specific areas within geography. In addition, the Geography and Education Research Group (GeogEd) functions as the main forum for issues pertinent to geography and education. A major thematic focus of GeogEd is pedagogic research in geographical contexts and encouraging the implementation of research and reflective practice by geography education practitioners at all levels. GeogEd is also interested in the geography of education itself and facilitates international conversations between educators around the world. If your professional home is geology or environmental science, look at bodies like the Geological Society or Institution of Environmental Science too.

Beyond the RGS-IBG, other online resources can help you learn from the teaching experiences of others and find good practice to apply to your own teaching. 'What works for learning and teaching in HE GEES?' is an online blog where contributors from the GEES community share ideas and practices for teaching geography, earth and environmental sciences. From short reflections to evidence-based studies of interventions, the blog highlights subject-specific work across the UK HE.

\section{Staying up to date with the latest research}

Amongst teaching practitioners across the subject, there is a vibrant and active publishing community, enabling new research and interventions to be shared and critically discussed. While research groups engage with the scholarship of teaching and learning within specific sub-disciplines, the Journal of Geography in Higher Education (JGHE) is a peer-reviewed platform for pedagogic scholarship right across the subject. The Journal is a great place to find up-to-date research in the field, and could also be an excellent platform on which to share your own work. Other journals cater specifically for Graduate Teaching Assistants (GTAs): for example, Postgraduate Pedagogies is an openaccess journal dedicated to discussing, synthesising and analysing the unique contribution that GTAs bring to the teaching and learning environment in HE.

\section{Rewarding and accrediting teaching excellence}

\section{AdvanceHE}

Fellowship of AdvanceHE (formerly the Higher Education Academy) provides recognition for teaching and learning practitioners in higher education, irrespective of your subject specialism. Four categories of fellowship are available: Associate Fellowship (AFHEA), Fellowship (FHEA), Senior Fellowship (SFHEA) and Principal Fellowship (PFHEA). Fellowship is aligned with the UK Professional Standards Framework (UKPSF), the national benchmark for teaching and learning, with successful applicants demonstrating how they meet one of the four descriptors. Fellowship can be achieved by submitting an application directly to AdvanceHE, or by completing an accredited programme of study, such as some postgraduate certificates or diplomas. If you are unsure which level of fellowship is right for you, the AdvanceHE website includes a Fellowship Category Tool which asks a series of questions aimed at enabling you to reflect on which category best reflects your current teaching and learning practices. There can be a cost to applying for fellowship, which varies depending on your institution's AdvanceHE membership status. However, as fellowship is widely recognised and is now even a requirement for some 
roles, it may be worth asking your institution about any support they can provide to help you achieve this recognition.

\section{Chartered Geographer}

Chartered Geographer (CGeog) is the only internationally recognised professional accreditation for those with competence, experience and professionalism in the use of geographical knowledge, understanding and skills in the workplace. Operated by the Royal Geographical Society (with IBG), there are currently $>850$ chartered geographers across all areas of the discipline. Applications are assessed by an independent panel against a framework of competencies, which focusses on innovation, professionalism, communication and how geographical knowledge, skills and understanding are applied in the workplace. There are six different post-nominals available to Chartered Geographers, which can be selected to reflect particular specialisms - CGeog (Econ); CGeog (Geomorph); CGeog (GIS); CGeog (Gl); CGeog (Teacher) - in addition to the general CGeog. Once CGeog status has been awarded, an annual continuing professional development (CPD) log of at least 35 hours (20 external and 15 internal) must be maintained and submitted. Chartered Geographers must also be a current Fellow of the Society.

Irrespective of your career stage, getting involved with communities of practice and networks across the subject can bring significant benefits and become a significant part of your reflexive teaching practice.

\section{Your next steps as an educator}

While this guide is by no means exhaustive, it is our hope that the concepts, ideas and resources it introduces will act as a springboard for further thinking about and reflection on your development as an educator - a process that will continue throughout your teaching career.

The higher education geography teaching and learning community is active and vibrant, and some of the great resources developed by members of the community have been signposted throughout. As a next step we strongly encourage you to engage with these and the excellent range of other high-quality work being undertaken by colleagues across the discipline.

Learning through geography helps us all to be more socially and environmentally sensitive, better informed, and more responsible as citizens and employees. As you seek to teach and inspire others with this diverse and fascinating subject, we hope this guide will be a helpful resource. 
○

\section{AdvanceHE (formerly the Higher Education} Academy, HEA)

(formally the Higher Education Academy, HEA) AdvanceHE is a member-led, sector-owned charity that works with higher education institutions across the world to improve higher education for staff, students and society. The focus of AdvanceHE is upon enhancing teaching and learning, effective governance, leadership development and tackling inequalities through work on EDI. See also Fellowship of AdvanceHE and UK Professional Standards Framework (UKPSF).

\section{Aims \\ Each degree programme will have a set of aims that explain the overall goals of the programme. These aims will relate to the programme's structure, student outcomes, placements (where relevant) and accrediting bodies (where relevant). Modules will also have a set of aims that explain the primary objectives of each specific module.}

\section{Assessment}

A generic term for a set of processes that measure a student's achievement of the intended learning outcomes in terms of knowledge acquired, understanding developed, skills gained and attributes demonstrated.

- Formative assessment: monitors students' learning to provide ongoing feedback that can be used by educators to improve their teaching and by students to improve their learning. Formative assessments do not count towards overall marks on a module.

- Summative assessment: evaluates students' learning by comparing it against a standard or benchmark (e.g. assessment criteria or grade descriptors). Summative assessments do count towards overall marks on a module.

\section{Assessment criteria}

Descriptions by which an assessor determines whether a student has demonstrated the achievement of the intended learning outcomes for a particular level.

\section{Assessment methods}

The different means by which a student's achievement of intended learning outcomes can be assessed. A wide range of methods may be used, but they must be appropriate to the intended learning outcomes being assessed.

\section{Chartered Geographer (CGeog)}

This is the RGS-IBG's internationally recognised accreditation for professionals who demonstrate, and continue to advance through professional development, their geographical expertise. See also RGS-IBG.

\section{Credit}

A quantitative measure of learning effort. The size of a module is measured by reference to student learning time, so that for every 10 credits a student is expected to spend 100 hours in programmed activities, private study or assessment. Credit is normally awarded for the achievement of a set of specified intended learning outcomes.

\section{External examiner}

An academic from another institution who checks and validates the marks and grading of degree awards, in consultation with the institution's own examination board.

\section{Fellowship of AdvanceHE}

AdvanceHE award four different categories of Fellowship: Associate Fellowship (AFHEA), Fellowship (FHEA), Senior Fellowship (SFHEA) and Principal Fellowship (PFHEA). These four categories reflect the wide range of professional practice carried out by those who teach and/or support learning in higher education. The four categories of Fellowship are awarded on the basis of evidence of personal professional practice relating to the UKPSF. See also UK Professional Standards Framework (UKPSF).

\section{Feedback}

The process by which students are informed of their strengths and weaknesses. The aim should be for high-quality and timely feedback to enable students to assess their progress and to improve upon it.

\section{Feed forward}

While feedback focuses on a student's current performance, feed forward looks ahead to subsequent assessments and offers constructive guidance on how to do better. A combination of both feedback and feed forward helps ensure that assessment has a developmental impact on learning. 


\section{GEES Subject Centre of the HEA}

The Geography, Earth and Environmental Science (GEES) Subject Centre of the Higher Education Academy was established in January 2000. It was led by its inaugural Director, Prof Brian Chalkley, who was succeeded by Prof Pauline Kneale. A restructure of the HEA led to closure of its subject centres, with support for teaching and learning being passed to the new GEES Discipline Lead, Prof Helen Walkington, between 2011-2013. As heads, all three were major contributors to the development and promotion of new ideas in teaching, learning and assessment in the GEES disciplines.

\section{Joint honours}

A type of degree where a student studies two subjects in equal depth; for example, Geography and Planning.

\section{Learning outcomes}

Each programme will have a set of learning outcomes that specifies the skills and knowledge that students are expected to develop over the course of the programme. Modules will also have specific skills outcomes and knowledge outcomes that specify what students will learn and what skills they will develop in each module.

\section{Lecture}

A lecture is a presentation intended to convey information about a topic. Traditionally, the lecturer will stand at the front of the room and recite information using some form of visual aid such as PowerPoint. Lectures can also involve a range of media such as videos and student participation in different formats. Geography lectures range in size from a handful of students to a few hundred.

\section{Module}

An element within a programme of study. Many modules focus on one aspect of geography in detail, such as Geomorphology, Social Geography or the Dissertation module. How much each module contributes to a degree varies and is normally stated in credits/points. Many UK undergraduate academic years consist of 120 credits and the total study time is expected to be 100 hours for each 10-credit module.

- Compulsory modules: modules that students must take in order to fulfil the requirements of the degree programme

- Optional modules/electives: modules which students choose to take because they suit their interests and career aspirations

\section{Matriculation}

This is the formal process for registering or enrolling at university. Some universities simply refer to this as registration or enrolment.

\section{Module leader}

The member of academic staff responsible for the module is the module leader. If students encounter difficulty in a module, they should refer to the module leader in the first instance. If they cannot resolve the difficulty with the module leader, they should consult the Degree Programme Director/Degree Scheme Leader.

\section{Postgraduate Certificate in Higher Education (PGCertHE)}

A PGCertHE is a Level 7 (Masters level equivalent) qualification designed to develop the practical skills and theoretical knowledge needed to become an effective educator in higher education. PGCertHE programmes are usually mapped onto the UK Professional Standards Framework (UKPSF), so those successfully completing the award will usually also receive Fellowship of AdvanceHE. See also Fellowship of AdvanceHE and UK Professional Standards Framework (UKPSF).

\section{Prerequisite}

A module that is required to be studied before undertaking a further module that assumes prior knowledge.

\section{Professional Standards Framework of AdvanceHE (UKPSF)}

The Professional Standards Framework was developed in the UK but has been used across the world to support the development of teaching and learning in higher education. It identifies components of successful teaching and learning.

\section{Programme specification}

A comprehensive description of all features of a programme of study, including the intended learning outcomes, the means by which those outcomes are achieved and demonstrated, the curriculum, criteria for admission, student support and regulations for assessment.

\section{Quality Assurance Agency for Higher Education (QAA)}

The independent body entrusted with monitoring and advising on standards and quality in UK higher education. See also Subject Benchmark Statements. 


\section{Roval Geographical Society (with the Institute of British Geographers)}

The RGS-IBG was founded in 1830 and is the learned society and professional body for geography, based in the United Kingdom.

\section{Semester}

A semester is a block of time in the undergraduate teaching year, typically lasting for anything from 12 to 18 weeks. Some modules will run in only one semester; other modules will run in both semesters. At many universities, both semesters end with a period of examinations. Many universities have both semesters and terms (and sometimes these names are used interchangeably).

\section{Seminar}

A small class where students discuss a specific topic with a lecturer or tutor. Seminars can take several formats. Some may be led by the lecturer or tutor and, on other occasions, students may be expected to lead the seminar (see also Tutorial).

\section{Subject Benchmark Statements}

A description of the nature and characteristics of programmes of study in a specific subject. The QAA's Subject Benchmark Statements represent general expectations about the standards for the award of qualifications at a given level, and they articulate the attributes and capabilities that those possessing such qualifications should be able to demonstrate. See also Quality Assurance Agency for Higher Education.

\section{Term}

The academic year at most UK universities runs from September or October to June or July, with a threeor four-week break around Christmas and Easter that divides the year into three terms. Some older universities have special names for the three terms, e.g. Michaelmas. Many universities have both terms and semesters.

\section{Tutor}

An academic staff member or teacher who is the main point of contact for a small group of students (tutees). Students may have several types of tutors (for example, an academic tutor and a pastoral tutor). Tutors are normally the first point of contact for any general queries about studying geography at university.

\section{Tutorial}

In some universities, the terms 'seminar' and 'tutorial' are used interchangeably. In some universities, tutorials involve only a very small group of students, and in others still, tutorials refer only to individual meetings between a tutor and a student. 


\section{References}

Bates, B. (2019). Learning Theories Simplified. London: SAGE Publications.

Biddulph, M. (2017). Inclusive geographies: the illusion of inclusion. Teaching Geography, 42(2), 46-48.

Biggs, J. (2001). Enhancing learning: A matter of style or approach? In: Sternberg, R.J. and Zhang, L. (Eds), Perspectives on Thinking, Learning, and Cognitive Styles. Abingdon: Routledge.

Bloom, B., Englehart, M., Furst, E., Hill, W., and Krathwohl, D. (1956). Taxonomy of Educational Objectives: The Classification of Educational Goals. Handbook I: Cognitive Domain. New York: Longman.

Bovill, C. (2020). Co-creating Learning and Teaching: Towards a Relational Pedagogy in Higher Education. St Albans: Critical Publishing.

Coffield, F., Mosely, D., Hall, E., and Eccleston, K. (2004). Learning Styles and Pedagogy in Post-16 Learning. A Systematic and Critical Review. London: Learning and Skills Research Centre. Retrieved from https://www.leerbeleving.nl/wp-content/ uploads/2011/09/learning-styles.pdf (accessed 21st May 2021).

Daigle, M. and Sundberg, J. (2017). From where we stand: Unsettling geographical knowledges in the classroom. Transactions of the Institute of British Geographers, 42(3), 338-341.

https://doi.org/10.1111/tran.12201

Domosh, M. (2015). Practising development at home:

Race, gender, and the "development" of the American South. Antipode, 47(4), 915-941.

https://doi.org/10.1111/anti.12138

Esson, J. and Last, A. (2019). Learning and teaching about race and racism in geography. In: Walkington, H., Hill, J., and Dyer S. (2019). Handbook for Teaching and Learning in Geography. Gloucestershire: Edward Elgar.

Esson, J. (2018). "The why and the white": racism and curriculum reform in British geography. Area, 52(4), 708-715. https://doi.org/10.1111/area.12475
Esson, J., Noxolo, P., Baxter, R., Daley, P., and Byron, M. (2017). The 2017 RGS-IBG chair's theme: decolonising geographical knowledges, or reproducing coloniality? Area, 49(3), 384-388. https://doi.org/10.1111/area.12371

Evans, C. (2013). Making Sense of Assessment Feedback in Higher Education. Review of Educational Research, 83(1), 70-120. https://doi.org/10.3102/0034654312474350

Everaert, P., Opdecam, E., and Maussen, S. (2017). The relationship between motivation, learning approaches, academic performance and time spent. Accounting Education, 26(1), 78-107. https://doi.org/10.1080/09639284.2016.1274911

Fleming, N.D. and Mills, C. (1992). Not Another Inventory, Rather a Catalyst for Reflection. To Improve the Academy, 11, 137-155.

https://doi.org/10.1002/j.2334-4822.1992.tb00213.x

Glass, M.R. (2015). International Geography Field Courses: Practices and Challenges. Journal of Geography in Higher Education, 39(4), 485-490. https://doi.org/10.1080/03098265.2015.1108044

Grierson, J. (2018). Geography a force for broadening the mind, says Michael Palin. The Guardian https:// www.theguardian.com/culture/2018/aug/06/michaelpalin-geography-force-broadening-mind-gcse-alevelentries-rise (accessed 20th December 2019).

Hall, E. and Wilton, R. (2017). Towards a relational geography of disability. Progress in Human Geography, 41(6), 727-744.

https://doi.org/10.1177/0309132516659705

Hall, T., Healey, M., and Harrison, M. (2004). Fieldwork and disabled students: discourses of exclusion and inclusion. Journal of Geography in Higher Education, 28(2), 255-280.

https://doi.org/10.1111/1475-5661.00050

HEA (2013). Feedback Toolkit. York: Higher Education Academy.

HEA (2016). Framework for Student Access, Retention, Attainment and Progression in Higher Education https://www.heacademy.ac.uk/download/ framework-student-access-retention-attainment-andprogression-higher-education (accessed 1st July 2021). 
Honey, P. and Mumford, A. (1986). Manual of Learning Styles. London: Peter Honey Publications.

Hughes, G., Smith, H., and Creese, B. (2015). Not seeing the wood for the trees: developing a feedback analysis tool to explore feed forward in modularised programmes. Assessment and Evaluation in Higher Education, 40(8), pp. 1079-1094.

https://doi.org/10.1080/02602938.2014.969193

Irons, A. (2007). Enhancing Learning through Formative Assessment and Feedback. Abingdon: Routledge.

Kirkwood, A. and Price, L. (2014). Technologyenhanced learning and teaching in higher education: what is 'enhanced' and how do we know? A critical literature review. Learning, Media and Technology, 39(1), 6-36.

https://doi.org/10.1080/17439884.2013.770404

Kolb, D.A. (1984). Experiential Learning: Experience as the Source of Learning and Development. New Jersey: Prentice-Hall.

Kolb, D.A. (2015). Experiential Learning: Experience as the Source of Learning and Development. New Jersey: Pearson.

Liu, C.H. and Matthews, R. (2005). Vygotsky's philosophy: Constructivism and its criticisms examined. International Education Journal, 6(3), 386-399.

MacKay, A. (2020). Out in the Field. Geography Directions. https://blog.geographydirections. com/2021/04/27/out-in-the-field/ (accessed 28th June 2021).

Mahtani, M. (2006). Challenging the ivory tower: proposing anti-racist geographies within the academy. Gender, Place and Culture, 13(1), 21-25.

https://doi.org/10.1080/09663690500530909

Marquis, E., Jung, B., Fudge Schormans, A., Lukmanji, S., Wilton, R., and Baptiste, S. (2016). Developing inclusive educators: enhancing the accessibility of teaching and learning in higher education. International Journal for Academic Development, 21(4), 337-349. https://doi.org/10.1080/1360144x.2016.1181071

Maslow, A.H. (1943). A theory of human motivation. Psychological Review, 50(4), 370-96.

Maslow, A.H. (1954). Motivation and Personality. New York: Harper and Row.
Meyer, J.H.F. and Land R. (2003). Threshold Concepts and Troublesome Knowledge: Linkages to Thinking and Practice within the Disciplines. ETL Occasional Report 4, May 2003. http://www.etl.tla.ed.ac.uk/docs/ ETLreport4.pdf (accessed 21st May 2018).

Miettinen, R. (2000). The concept of experiential learning and John Dewey's theory of reflective thought and action. Journal of Lifelong Learning, 19, 54-72. https://doi.org/10.1080/026013700293458

Morris, T.H. (2019). Experiential learning - a systematic review and revision of Kolb's model. Interactive Learning Environments, 28(8), 1064-1077. https://doi.org/10.1080/10494820.2019.1570279

Moses T. (2020). 5 reasons to let students keep their cameras off during Zoom classes. The Conversation. https://theconversation.com/5-reasons-to-let-studentskeep-their-cameras-off-during-zoom-classes-144111 (accessed 30th June 2020).

Palin, L. (2020). Lecturers, stop forcing us to turn our cameras on. The Tab. https://thetab.com/uk/ cardiff/2020/10/14/lecturers-stop-forcing-us-to-turnour-cameras-on-53410 (accessed 30th June 2020).

Pavlov, I.P. (1955). Selected Works. Moscow: Foreign Languages Publishing House.

Piaget, J. (1936). Origins of Intelligence in the Child. London: Routledge and Kegan Paul.

Price, M., Rust, C., O'Donovan, B., Handley, K., and Bryant, R. (2012). Assessment Literacy: The Foundation for Improving Student Learning. Wheatley: Oxford Brookes University.

QAA (2022). Subject Benchmark Statement for Geography. Gloucestershire: QAA.

RGS-IBG (2017). Nick Crane's letter promoting further study and careers in geography https://www.rgs. org/schools/teaching-resources/nick-crane-s-letterpromoting-further-study-and-ca/ (accessed 13th November 2020).

RGS-IBG (2020). Principles for Undergraduate Field Courses. https://www.rgs.org/research/highereducation-resources/fieldprinciples/ (accessed 28th June 2021).

RGS-IBG (2021) Advice and Training for Fieldwork and Expeditions. https://www.rgs.org/in-the-field/advicetraining/ (accessed 3rd August 2021).

Schön, D. (1994). The Reflective Practitioner: How Professionals Think in Action. Farnham: Ashgate Publishing Limited. 
Schulman, L.S. (2005). Signature Pedagogies in the Professions. Daedalus, 134(3), 52-59.

https://doi.org/10.1162/0011526054622015

Seaman, J., Brown, M., and Quay, J. (2017). The evolution of experiential learning theory: tracing lines of research in the JEE. Journal of Experiential Education, 40, NP1-NP21.

https://doi.org/10.1080/026013700293458

Skinner, B.F. (1938). The Behavior of Organisms: An Experimental Analysis. New York: Appleton-Century.

Skinner, B.F. (1948). Walden Two. New York:

Macmillan.

Skinner, B.F. (1971). Beyond Freedom and Dignity. New York: Knopf.

Stonewall (2021). Workplace Allies Programme. https://www.stonewall.org.uk/workplace-alliesprogramme (accessed 2nd July 2021).

Thorndike, E.L. (1905). The Elements of Psychology. New York: A.G. Seiler.

Tuck, E. and Yang, K.W. (2012). Decolonization is not a metaphor. Decolonization: Indigeneity, Education and Society, 1(1), 1-40.

Vygotsky, L.S. (1978). Mind in Society: the Development of Higher Psychological Processes. Massachusetts: Harvard University Press.

Walkington, H., Hill, J., and Dyer S. (2019). Handbook for Teaching and Learning in Geography. Gloucestershire: Edward Elgar.

Yorke, M. and Knight, P. (2006). Embedding Employability into the Curriculum: Learning and Employability Series One. York: Higher Education Academy. 


\section{Royal Geographical Society (with IBG)}

1 Kensington Gore London SW7 2AR
T $+44(0) 2075913000$
E rhed@rgs.org
w www.rgs.org 